\title{
Pre-Analysis-Plan; Energy Policy Preferences and Compensation Policies in Germany
}

\author{
Mares, Isabela * \\ Scheve, Kenneth ${ }^{\dagger}$ \\ Toenshoff, Christina ${ }^{\ddagger}$ \\ isabela.mares@yale. edu \\ kenneth.scheve@yale.edu \\ ctoensh@stanford.edu
}

December, 2021

\section{Contents}

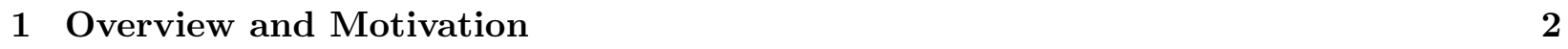

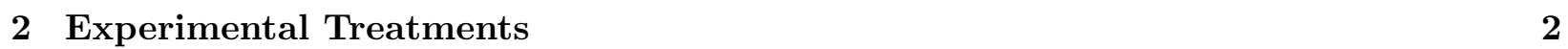

2.1 Experimental Design 1 . . . . . . . . . . . . . . . . . . . . . . . 2

2.2 Experimental Design $2 \ldots \ldots \ldots \ldots \ldots \ldots \ldots$

2.3 Experimental Design $3 \ldots \ldots \ldots \ldots \ldots \ldots$

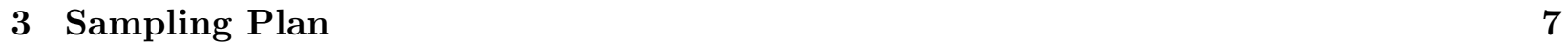

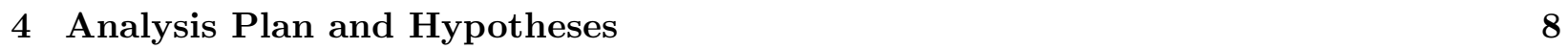

4.1 Analysis Experiment $1 \ldots \ldots \ldots \ldots \ldots \ldots$

$4.1 .1 \quad$ Heterogeneity Analysis Experiment 1. . . . . . . . . . . . . . . . . . 9

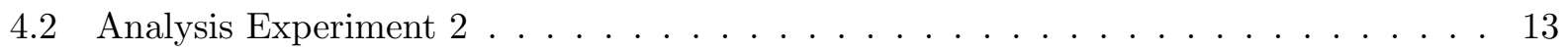

4.2 .1 Heterogeneity Analysis Experiment 2 . . . . . . . . . . . . . . 14

4.3 Analysis Experiment $3 \ldots \ldots \ldots \ldots \ldots \ldots$

$4.3 .1 \quad$ Interactions between Conjoint Attributes Experiment 3 . . . . . . . . . . . 18

$\begin{array}{llll}4.3 .2 & \text { Expected Effects of Vignette Texts, Experiment } 3 & \ldots\end{array} \ldots \ldots$. . . . . . . 19

4.3 .3 Heterogeneity Analysis Experiment 3 . . . . . . . . . . . . . . . . 20

\begin{tabular}{ll}
\hline References & 33
\end{tabular}

*Arnold Wolfers Professor of Political Science, Yale University

${ }^{\dagger}$ Dean Acheson Professor of Political Science and Global Affairs, Yale University

${ }^{\ddagger}$ PhD Candidate Political Science, Stanford University 


\section{Overview and Motivation}

Transitioning away from carbon-intensive to more renewable energy sources is one key lever through which countries can mitigate climate change. At the same time, such energy transitions create losers among consumers, investors and workers. In this study, we conduct three survey experiments designed to test how compensation measures offered by the government change public support for a transition to greener energy sources. The survey is fielded in Germany, just before the 2021 federal election.

This pre-analysis plan is being filed in December of 2021 after data collection in September 2021 but before any inspection of the survey data. An important feature of the study is to analyze opinions in the context of a national election in which energy and climate issues were salient. It was not possible to file the pre-analysis plan between our pilot and the latest start date that would allow all respondents to complete the survey before the German election.

\section{Experimental Treatments}

Respondents participate in three survey experiments. Treatment assignment for each experiment is orthogonal to the other experiments. Respondents are further presented with a mock vignette experiment, designed to test attention. The order in which the experiments and the mock vignette are presented to participants is randomized.

\subsection{Experimental Design 1}

The first experiment is a conjoint-experiment that presents individuals with a choice between two hypothetical candidates for the upcoming federal election. The experiment randomly varies 5 candidate characteristics: party, gender, position on energy policy, position on social policy, and position on migration policy.

Each respondent will repeat the comparison process of this experimental design five times. The outcome measure is a simple binary choice between the two candidates. The possible values for all five factors are listed in table 1. Figure 1 presents an example conjoint table.

\subsection{Experimental Design 2}

In a second experiment, we use a vignette design to test the effect of different forms of compensation on support for the energy transition. In this experiment, we focus on the transition away from coal, as this particular policy goes hand in hand with a variety of compensation measures. Respondents are asked to watch short videos that present them with information on the exit from coal. First, all participants receive information on Germany's current plans to exit coal. Among other things, the text mentions all the societal groups that could be considered losers of the exit from coal consumers, workers, investors, and those living in coal regions.

The control group receives no further information. Three treatment groups receive information on different forms of compensation: compensation for consumers (Treatment 1), compensation for 
Bitte schauen Sie dich die folgenden Profile hypothetischer Kandidaten für die Bundestagswahl an:

\begin{tabular}{|c|c|c|}
\hline & Kandidat/in 1 & Kandidat/in 2 \\
\hline Geschlecht & Weiblich & Männlich \\
\hline Partei & Bündnis $90 /$ Grūnen & FDP \\
\hline Energiepolitik & $\begin{array}{l}\text { Unterstützt eine } \\
\text { Weiterführung der } \\
\text { Energiewende im } \\
\text { derzeit vorgesehenen } \\
\text { Tempo, aber fordert } \\
\text { erhöhte Zuschüsse } \\
\text { für energieintensive } \\
\text { Unternehmen, um } \\
\text { deren } \\
\text { Wettbewerbsfähigkeit } \\
\text { zu bewahren }\end{array}$ & $\begin{array}{l}\text { Unterstützt eine } \\
\text { Weiterführung der } \\
\text { Energiewende im } \\
\text { derzeit vorgesehenen } \\
\text { Tempo, aber fordert } \\
\text { erhöhte Zuschüsse } \\
\text { für energieintensive } \\
\text { Unternehmen, um } \\
\text { deren } \\
\text { Wettbewerbsfähigkeit } \\
\text { zu bewahren }\end{array}$ \\
\hline Sozialpolitik & $\begin{array}{c}\text { Unterstützt eine } \\
\text { Erhebung des } \\
\text { Rentenalters auf } 68\end{array}$ & $\begin{array}{l}\text { Hält Frührente für } \\
\text { akzeptabel da es } \\
\text { nicht genügend } \\
\text { Stellen für } \\
\text { Arbeitsuchende gibt }\end{array}$ \\
\hline Migrationspolitik & $\begin{array}{l}\text { Unterstützt effektivere } \\
\text { Maßnahmen um } \\
\text { Flüchtlinge aus } \\
\text { Deutschland } \\
\text { fernzuhalten }\end{array}$ & $\begin{array}{l}\text { Unterstützt effektivere } \\
\text { Maßnahmen, die } \\
\text { Flüchtlinge mit } \\
\text { legalem } \\
\text { Aufenthaltsrecht in } \\
\text { Deutschland } \\
\text { eingliedern }\end{array}$ \\
\hline
\end{tabular}

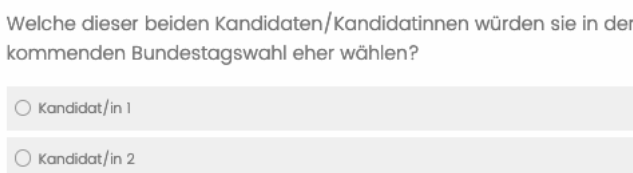

Figure 1: Example Table Experiment 1

investors (Treatment 2), compensation for workers (Treatment 3) and compensation for coal regions as a whole (Treatment 4$)$.

Links to the videos and English translations of their transcripts can be found below:

\section{Control Group Video}

English Transcript: "The German Coal Exit. Germany is exiting coal. In 2020, the federal and regional governments reached an agreement on the time-line of Germany's exit from coal. The plan determined that Germany will fully exit coal by 2038. Coal is a major source of carbon emissions in Germany, and transitioning away from coal is an important step if Germany wants to achieve its climate goals. While exiting coal helps the climate and might promote new, green industries, some will experience negative consequences. Investors who have invested money in coal companies might lose money. Workers who are employed in the coal industry will lose their jobs. This can be especially difficult for older workers, who find it hard to retrain after decades in the same occupation. Exit from coal can also pose challenges for coal regions as a whole. As a major industry breaks away, this has negative effects on 


\begin{tabular}{|c|c|c|}
\hline$\underline{\text { Label }}$ & $\frac{\text { German }}{\text { Party (P) }}$ & English Translation \\
\hline $\begin{array}{l}\text { party } 1 \\
\text { party2 } \\
\text { party3 } \\
\text { party } 4 \\
\text { party5 } \\
\text { party6 }\end{array}$ & $\begin{array}{l}\text { SPD } \\
\text { CDU/CSU } \\
\text { Die Linke } \\
\text { Bündnis 90/Grüne } \\
\text { AfD } \\
\text { FDP }\end{array}$ & $\begin{array}{l}\text { SPD } \\
\text { CDU/CSU } \\
\text { The Left } \\
\text { Bündnis } 90 / \text { Greens } \\
\text { AfD } \\
\text { FDP }\end{array}$ \\
\hline & Gender $(G)$ & \\
\hline $\begin{array}{l}\text { male } \\
\text { female }\end{array}$ & $\begin{array}{l}\text { Männlich } \\
\text { Weiblich }\end{array}$ & $\begin{array}{l}\text { Male } \\
\text { Female }\end{array}$ \\
\hline & Energy Policy Position (EP) & \\
\hline esame & $\begin{array}{l}\text { Glaubt, dass die derzeitige Energiewende zu schnell ist und } \\
\text { unterstützt die Verlangsamung der Maßnahmen, mit denen } \\
\text { Deutschland CO2-Neutralität erreichen will. } \\
\text { Unterstützt eine Weiterführung der Energiewende im derzeit } \\
\text { vorgesehenen Tempo }\end{array}$ & $\begin{array}{l}\text { Considers that the current energy transition is happening too } \\
\text { fast and supports slowing down the measures taken by Germany } \\
\text { to achieve carbon neutrality } \\
\text { Supports continuing the Energiewende at the current high } \\
\text { speed }\end{array}$ \\
\hline ecompens & $\begin{array}{l}\text { Unterstützt eine Weiterführung der Energiewende im derzeit } \\
\text { vorgesehenen Tempo, aber fordert erhöhte Zuschüsse für En- } \\
\text { ergiekosten für Personen mit geringem Einkommen. }\end{array}$ & $\begin{array}{l}\text { Supports continuing the Energiewende at the current high } \\
\text { speed, but would like to increase subsidies for the energy costs } \\
\text { of persons with low incomes }\end{array}$ \\
\hline ecompet & $\begin{array}{l}\text { Unterstützt eine Weiterführung der Energiewende im derzeit } \\
\text { vorgesehenen Tempo, aber fordert erhöhte Zuschüsse für en- } \\
\text { ergieintensive Unternehmen, um deren Wettbewerbsfähigkeit zu } \\
\text { bewahren. }\end{array}$ & $\begin{array}{l}\text { Supports continuing the Energiewende at the current high } \\
\text { speed, but would like to increase subsidies for enterprises to } \\
\text { offset the implications for competitiveness of this transition }\end{array}$ \\
\hline & Social Policy Position (SP) & \\
\hline $\begin{array}{l}\text { p68 } \\
\text { pnone } \\
\text { pearly }\end{array}$ & $\begin{array}{l}\text { Unterstützt eine Anhebung des Rentenalters auf } 68 \text {. } \\
\text { Unterstützt keine Reformen des Rentenalters. } \\
\text { Hält Frührente für akzeptabel, da es nicht genügend Stellen für } \\
\text { ältere Arbeiter und Arbeitssuchende gibt. }\end{array}$ & $\begin{array}{l}\text { Supports raising the retirement age to } 68 \\
\text { Supports no changes to the policy of old age insurance } \\
\text { Considers that early retirement practices are acceptable, given } \\
\text { the lack of employment opportunities for elderly workers }\end{array}$ \\
\hline & Migration Policy Position (MP) & \\
\hline mmore & $\begin{array}{l}\text { Unterstützt neue legale Wege für die Einreise von Flüchtlingen } \\
\text { aus Kriegsgebieten nach Deutschland. }\end{array}$ & $\begin{array}{l}\text { Supports creating legal pathways for refugees from war zones } \\
\text { to enter Germany. }\end{array}$ \\
\hline mbar & $\begin{array}{l}\text { Unterstützt effektivere Maßnahmen um Flüchtlinge aus } \\
\text { Deutschland fernzuhalten. }\end{array}$ & $\begin{array}{l}\text { Supports erecting more effective barriers to keep refugees out } \\
\text { of Germany. }\end{array}$ \\
\hline maid & $\begin{array}{l}\text { Unterstützt mehr finanzielle Hilfe für die Errichtung von } \\
\text { Flüchtlingslagern in Ländern, die an Kriegsgebiete angrenzen. }\end{array}$ & $\begin{array}{l}\text { Supports sending aid to countries closer to conflict zones to } \\
\text { erect refugee camps there. }\end{array}$ \\
\hline
\end{tabular}

Table 1: Conjoint Experiment 1 Levels of Candidate Attributes

many households and businesses in the region. Lastly, consumers might face higher energy prices due to the exit from coal."

T1 Consumer Compensation Treatment Video

English Transcript: Control group video + "The government has agreed on measures that aim to avoid these negative consequences for consumers. The government has promised to subsidize energy costs for German households if prices rise due to the exit from coal. This will make sure that German families don't see an increase in their energy bills as a result of this policy."

T2 Investor Compensation Treatment Video

English Transcript: Control group video + "To avoid the negative financial consequences for investors, the government has agreed to pay compensation. According to the agreement, operators of coal fired powerplants will receive money for plant closures. Operators of lignite fired powerplants will receive direct compensation."

T3 Worker Compensation Treatment Video

English Transcript: Control group video + "In order to avoid the coal exit's negative consequences for workers in the coal industry, the government has decided on a number of measures. For those workers close to retirement, the government will pay five years of compensation. This will count towards their retirement benefits. For younger workers, the government is giving firms funds to provide retraining. In addition, many new jobs are being created in green industries. The government will help former coal workers to enter these promising new careers."

T4 Coal Region Compensation Treatment Video 
English Transcript: Control group video + "To help coal regions with the exit from coal, the government has agreed on measures. The regional, federal and EU governments will allocate structural aid to coal regions. The money will be used to help these regions attract and develop new growth industries that can replace former coal mining. For example, the funds will be used to invest in new infrastructure and better education. This will help attract new businesses to the regions. Former coal mining sites will also be turned into places of recreation and tourism with the help of government money. The government has further promised to locate new offices of federal agencies in the affected regions. This will provide a boost to local employment."

Two outcome variables are used to test how different forms of compensation affect support for a (rapid) exit from coal. First, we ask for participants' support or opposition to a full exit from coal. We then ask individuals to choose the best year for the exit from coal on a slider scale (2021-2050). Earlier years indicate more support for a rapid transition away from coal.

\subsection{Experimental Design 3}

A third experiment tests individuals' willingness to pay for climate policy. Respondents are randomly assigned to the control group (C), or one of two treatment groups: the compensation treatment (T1) or the competitiveness treatment (T2). First, all respondents are asked to read a short text on carbon pricing. The treatment groups each read an additional paragraph. Below are the English translations of the control and treatment texts:

C One key way to reduce carbon emissions is to put a price on carbon. By making firms and households pay for each unit of carbon they emit, the government can provide a powerful incentive to reduce carbon emissions. In order to achieve their climate goals, the German federal government and the EU are thinking of raising the price of carbon. As a result, some households might struggle to pay their bills. Further, some domestic firms might become less competitive than their foreign counterparts.

T1 Control + To reduce the negative financial impact that a high price on carbon can have on households, the government can decide to redistribute some or all of the money it raises from higher carbon prices back to consumers.

T2 Control + To avoid a loss of competitiveness that a high price on carbon can have on domestic firms, governments can pair carbon pricing with carbon border adjustment taxes. These taxes charge foreign companies if they don't have to pay a tax on carbon in their home country a tariff or tax based on how much carbon they emit. With this policy domestic firms can compete fairly regardless of whether other countries adopt carbon pricing policies.

After reading the information on carbon pricing, respondents are presented with a conjoint experiment, which asks them to pick one of two hypothetical climate policy plans. The plans randomly vary along four dimensions: cost, effectiveness, compensation measures and competitiveness measures. A full list of conjoint inputs can be found in table 2 and an example conjoint table is depicted in figure 2. While individuals only read one excerpt at the beginning of the experiment, the conjoint task is repeated five times. The outcome measure is a simple binary choice between the two plans. 
Politiker debattieren verschiedene Politikvorschläge, die $\mathrm{CO} 2$ Emissionen verringern und damit den Klimawandel bekämpfen sollen. Wir zeigen Ihnen nun eine Reihe von hypothetischen Plänen und möchten wissen, welchen Plan Sie bevorzugen würden. Bitte wählen Sie einen Plan aus, auch wenn Ihnen keiner der Pläne gefällt.

\begin{tabular}{|c|c|c|}
\hline & Plan 1 & Plan 2 \\
\hline $\begin{array}{c}\text { Kostenanstieg pro } \\
\text { Jahr }\end{array}$ & 150 Euro pro Jahr & 350 Euro pro Jahr \\
\hline Effektivität & $\begin{array}{l}\text { Die meisten Experten } \\
\text { glauben, dass } \\
\text { Deutschland mit diesem } \\
\text { Plan seine } \mathrm{CO} 2 \\
\text { Emissionen bis } 2030 \mathrm{um} \\
25 \text { Prozent reduzieren } \\
\text { könnte }\end{array}$ & $\begin{array}{l}\text { Die meisten Experten } \\
\text { glauben, dass } \\
\text { Deutschland mit } \\
\text { diesem Plan seine } \\
\text { CO2 Emissionen bis } \\
2030 \text { um } 55 \text { Prozent } \\
\text { reduzieren könnte }\end{array}$ \\
\hline Entschädigung & $\begin{array}{l}\text { Keine Veränderung von } \\
\text { bestehenen } \\
\text { Entschädigungszahlungen }\end{array}$ & $\begin{array}{l}\text { Hohe } \mathrm{CO} 2 \text { Dividende, } \\
\text { die an alle Bürger die } \\
\text { gleiche Summe zahlt } \\
\text { und sie dadurch für } \\
\text { höhere Energiekosten } \\
\text { durch Klimapolitik } \\
\text { entschädigt. }\end{array}$ \\
\hline Wettbewerbsförderung & $\begin{array}{l}\text { Umweltkapitel in } \\
\text { zukünftigen } \\
\text { Handelsabkommen um } \\
\text { andere Länder zur } \mathrm{CO} 2 \\
\text { Bepreisung zu verpflichten }\end{array}$ & $\begin{array}{l}\text { Keine Veränderung } \\
\text { von bestehender } \\
\text { Wettbewerbsförderung }\end{array}$ \\
\hline
\end{tabular}

Welchen Plan würden Sie bevorzugen?

Plan 1

Plan 2

Figure 2: Example Table Experiment 3

\begin{tabular}{|c|c|}
\hline Label & German \\
\hline & Estimated increase average household cost (C) \\
\hline $\mathrm{cl}$ & 150 Euro pro Jahr \\
\hline $\mathrm{cml}$ & 300Euro pro Jahr \\
\hline $\mathrm{cmh}$ & 600 Euro pro Jahr \\
\hline \multirow[t]{2}{*}{ ch } & 1200 Euro pro Jahr \\
\hline & Effectiveness (E) \\
\hline el & $\begin{array}{l}\text { Die meisten Experten glauben, dass Deutschland mit diesem Plan } \\
\text { seine CO2 Emissionen bis } 2030 \text { um } 25 \% \text { reduzieren könnte. }\end{array}$ \\
\hline \multirow[t]{2}{*}{ eh } & $\begin{array}{l}\text { Die meisten Experten glauben, dass Deutschland mit diesem Plan } \\
\text { seine CO2 Emissionen bis } 2030 \text { um } 55 \% \text { reduzieren könnte. }\end{array}$ \\
\hline & Compensation for Consumers (CS) \\
\hline $\mathrm{cnc}$ & Keine Veränderung von bestehenen Entschädigungszahlungen \\
\hline clls & $\begin{array}{l}\text { Niedrige CO2 Dividende, die an alle Bürger die gleiche Summe } \\
\text { zahlt und sie dadurch für höhere Energiekosten durch Klimapoli- } \\
\text { tik entschädigt. }\end{array}$ \\
\hline chls & $\begin{array}{l}\text { Hohe CO2 Dividende, die an alle Bürger die gleiche Summe zahlt } \\
\text { und sie dadurch für höhere Energiekosten durch Klimapolitik } \\
\text { entschädigt. }\end{array}$ \\
\hline $\operatorname{clp}$ & $\begin{array}{l}\text { Niedrige CO2 Dividende, die Bürger für höhere Energiekosten } \\
\text { durch Klimapolitik entschädigt und höhere Summen an Menschen } \\
\text { mit niedrigem Einkommen zahlt. }\end{array}$ \\
\hline \multirow[t]{2}{*}{$\operatorname{chp}$} & $\begin{array}{l}\text { Hohe } \mathrm{CO} 2 \text { Dividende, die Bürger für höhere Energiekosten durch } \\
\text { Klimapolitik entschädigt und höhere Summen an Menschen mit } \\
\text { niedrigem Einkommen zahlt. }\end{array}$ \\
\hline & Measures to Ensure Competitiveness (CT) \\
\hline $\operatorname{ctnc}$ & Keine Veränderung von bestehender Wettbewerbsförderung \\
\hline cbt & $\begin{array}{l}\text { CO2 Grenzsteuer, die die Preise von Gütern anpasst, die in } \\
\text { Ländern mit weniger strenger Klimapolitik produziert wurden. }\end{array}$ \\
\hline pta & $\begin{array}{l}\text { Umweltkapitel in zukünftigen Handelsabkommen um andere } \\
\text { Länder zur CO2 Bepreisung zu verpflichten }\end{array}$ \\
\hline
\end{tabular}

English Translation

150 Euros per year 300 Euros per year 600 Euros per year 1200 Euros per year

Most experts think this plan will reduce Germany's CO2 emissions by $25 \%$ by 2030

Most experts think this plan will reduce Germany's CO2 emissions by $55 \%$ by 2030

No change in compensation policies

Low carbon dividend that pays the same amount to everyone and compensates for higher energy prices from climate policies.

High carbon dividend that pays the same amount to everyone and compensates for higher energy prices from climate policies.

Low carbon dividend that pays the more to those with lower incomes and compensates for higher energy prices from climate policies.

High carbon dividend that pays the more to those with lower incomes and compensates for higher energy prices from climate policies.

No change in competitiveness policies.

Carbon border tax that adjusts the prices of goods produced in countries with less stringent climate policies than Germany.

Environmental chapters in future trade agreements to commit other countries to carbon pricing.

Table 2: Experiment 3 Levels of Plan Attributes 


\section{Sampling Plan}

Data Collection Procedure:

Data is collected through the survey firm Respondi. Individuals are randomly chosen from an existing panel of adult German respondents. The data is collected using quotas along four dimensions to ensure representativeness: 1) age, 2) region (16 Laender), 3) income, and 4) gender.

Sample Size:

The final sample size is 2000. Respondents who fail the survey's last attention check are excluded from the study and are not part of the sample.

Attention Checks:

We employ two types of attention checks: First, we present individuals with a mock vignette text, which is the same for all participants. Respondents are then asked to answer three factual questions about the text. The mock vignette we employ was initially developed and tested by Kane et al. (2020). We translate the mock vignette text into German and replace American organizations referred to in the questions with their German/European counterparts. The English text can be found below. In a second attention check, we use a traditional attention check question at the end of our experimental modules. Individuals who do not answer this question correctly are excluded from our survey.

\section{Mock Vignette Text}

Please read the following excerpt from a magazine article.

A Passage from a Recent Magazine Article: The International Maritime Organization (IMO), the industry's regulator, will require all ships to cut the level of sulfur in their engine emissions beginning January 1st. The limit reduces the sulfur dioxide (SO2) that ships emit into the atmosphere via the ship's funnel. Therefore, policymakers expect that there will be a reduction in the SO2 that finds its way into the air. It may seem like a small change, but the effects will ripple across the oil value chain. For example, many ships will comply by investing in scrubbers that strip the sulfur out of the exhaust. But, there is a lot of worry over the possibility that ships will divert air pollutants directly into the sea, leading to greater pollution in the ocean. The other issue is that the regulation does not currently require refiners to remove the sulfur at its origin.

Q1 What was the topic of the magazine excerpt you just read?

- Industrial chemical solutions • New steel tariffs • Sulfur reductions • Plane cargo limits

- Air travel regulations • Fishing licensing reform

Q2 Which organization, according to the magazine article, was responsible for the rule change?:

- Deutsche Forschungsgemeinschaft (German Federal Science Foundation) • International Maritime Organization • International Monetary Fund • Industrial Manufacturing Organization • Deutscher Wetterdienst (German meteorological service) • Bundesrechnungshof (Federal Audit Office)

Q3 What, according to the magazine article, is a possible consequence of the rule change being discussed 
- Increased pollution into the ocean • Decreased profits for businesses • Increased corruption in government $\bullet$ Increased health risks of citizens $\bullet$ All of the above $\bullet$ None of the above

\section{Analysis Plan and Hypotheses}

\subsection{Analysis Experiment 1}

The outcome variable for the first experiment is respondents' choice between the two candidates they were presented with. We calculate the average marginal component effects (AMCEs) of all the attributes in our experiment. These quantities provide each attribute's estimated effect on the probability of choosing a candidate (Hainmueller, Hopkins, \& Yamamoto, 2014).

To conduct this analysis, we first reshape the data. Respondents are presented with five conjoint tables that each compare 2 candidates. We code each choice as a binary variable for each of the candidates ( 1 if candidate was chosen, 0 if candidate was not chosen) and create a long-form dataset with $5^{*} 2^{*}$ n rows, where each row represents an individual-candidate-choice. To account for the fact that responses from the same individuals likely have correlated error terms, we cluster all standard errors at the respondent-level.

For our analysis, we then set the following default categories:

- Party: CDU/CSU

- Gender: female

- Energy Policy Position: esame (no change to current policy)

- Social Policy Position: pnone (no change to current policy)

- Migration Policy Position: maid (sending more aid to countries closer to conflict zones)

AMCEs measure the underlying preferences in society. These will differ across population subgroups. We thus test two-sided hypotheses for all AMCEs, unless otherwise specified below.

In our analysis, we are particularly interested in the AMCEs of energy policy attributes. One primary hypothesis we test is whether support for slowing down the energy transition increases a candidate's probability of being chosen.

1.

$$
\begin{aligned}
& H_{0}:\left(p_{\text {cand }} \mid E P_{i}=\text { esame }\right)=\left(p_{\text {cand }} \mid E P_{i}=\text { eslow }\right) \\
& H_{a}:\left(p_{\text {cand }} \mid E P_{i}=\text { esame }\right) \neq\left(p_{\text {cand }} \mid E P_{i}=\text { eslow }\right)
\end{aligned}
$$

We are further interested in the component effects of compensation and competitiveness policies, compared to the status quo. Here, we specify one-sided hypotheses, as we expect that both compensation and competitiveness policies in the context of the energy transition should increase support for a candidate. 
2 .

$$
\begin{aligned}
& H_{0}:\left(p_{\text {cand }} \mid E P_{i}=\text { ecompens }\right)=\left(p_{\text {cand }} \mid E P_{i}=\text { esame }\right) \\
& H_{a}:\left(p_{\text {cand }} \mid E P_{i}=\text { ecompens }\right)>\left(p_{\text {cand }} \mid E P_{i}=\text { esame }\right)
\end{aligned}
$$

3.

$$
\begin{aligned}
& H_{0}:\left(p_{\text {cand }} \mid E P_{i}=\text { ecompet }\right)=\left(p_{\text {cand }} \mid E P_{i}=\text { esame }\right) \\
& H_{a}:\left(p_{\text {cand }} \mid E P_{i}=\text { ecompet }\right)>\left(p_{\text {cand }} \mid E P_{i}=\text { esame }\right)
\end{aligned}
$$

Lastly, we test whether the AMCEs for competition and compensation policies in the energy transition differ from each other. We have no strong priors on the direction of this difference. We thus conduct a hypothesis test with a two-sided alternative hypothesis.

4.

$$
\begin{aligned}
& H_{0}:\left(p_{\text {cand }} \mid E P_{i}=\text { ecompens }\right)=\left(p_{\text {cand }} \mid E P_{i}=\text { ecompet }\right) \\
& H_{a}:\left(p_{\text {cand }} \mid E P_{i}=\text { ecompens }\right) \neq\left(p_{\text {cand }} \mid E P_{i}=\text { ecompet }\right)
\end{aligned}
$$

\subsubsection{Heterogeneity Analysis Experiment 1}

In addition to our analysis of the full sample, we test heterogeneity among groups of theoretical interest. The analyses described above are repeated for the following subgroups:

\section{Party identity}

- Voted (CDU/CSU; SPD; Buendnis 90/Greens; FDP; The Left; AfD) with their second vote in 2021

- Voters that switched to the Greens between 2017 and 2021

- Voters that switched to the AfD between 2017 and 2021

\section{Political and Social Attitudes}

- Individuals with (high/ low) level of authoritarianism

- Individuals who (support/ oppose) the welfare state

- Individuals with (high/low) trust in the government

- Individuals that (support/ oppose) high levels of government intervention

- Individuals that report being (left-wing/ centrist/ right-wing)

- Individuals who (believe / do not believe) in man-made climate change

Employment Characteristics 
- Working for an employer that (does/ does not) export

- Working for an employer that (does/ does not) engage in FDI

- Working for an employer that (does/ does not) compete with foreign imports

- Working in the (public/ private) sector

- Working in a sector that is a (high/low) emitter of $\mathrm{CO} 2$

- (Blue collar / White collar) workers

\section{Other Characteristics}

- Income quintile

- Gender

- Age

- Individuals residing in (East/West) Germany

- Individuals who were hit by the summer floods (identified by postal code)

Heterogeneity between these sets of sub-groups is tested in the following ways: For all of subgroups, we calculate the conditional average marginal component effect (CAMCEs) of our main attributes of interest by subsetting to a group and repeating the regression analysis specified above. Further, to compare the CAMCEs between sets of subgroups, we run OLS regressions that interact the energy policy attributes with subgroup characteristics. For all analyses, we continue to cluster standard errors at the respondent level. In regressions with interaction terms, we also use heteroskedasticity robust standard errors. For variables that measure attributes on a scale with more than two levels, e.g. trust in government, we run two analyses for robustness: First, we recode the variable into a binary indicator of high-low and use this binary variable to analyse sub-samples and run regressions with interaction effects. Second, we also run regressions with interaction using the original variable with more than two levels.

For most of the subgroup comparisons, we have no strong priors on the direction of the difference in CAMCE. We thus employ two-sided alternative hypotheses unless otherwise specified. We do have clear expectations for some of the subgroups:

We expect the CAMCE for continuation of the energy transition, as well as compensation and competitiveness measures to be larger for individuals who prefer a high degree of government intervention (gvtint $=$ high $)$ :

1.

$$
\begin{gathered}
H_{0}:\left(\left(p_{\text {cand }} \mid E P_{i}=\text { esame }\right)-\left(p_{\text {cand }} \mid E P_{i}=\text { eslow }\right) \mid \text { gvtint }=\text { low }\right)= \\
\quad\left(\left(p_{\text {cand }} \mid E P_{i}=\text { esame }\right)-\left(p_{\text {cand }} \mid E P_{i}=\text { eslow }\right) \mid \text { gvtint }=\text { high }\right) \\
H_{a}:\left(\left(p_{\text {cand }} \mid E P_{i}=\text { esame }\right)-\left(p_{\text {cand }} \mid E P_{i}=\text { eslow }\right) \mid \text { gvtint }=\text { low }\right)< \\
\quad\left(\left(p_{\text {cand }} \mid E P_{i}=\text { esame }\right)-\left(p_{\text {cand }} \mid E P_{i}=\text { eslow }\right) \mid \text { gvtint }=\text { high }\right)
\end{gathered}
$$


2 .

$$
\begin{aligned}
& H_{0}:\left(\left(p_{\text {cand }} \mid E P_{i}=\text { ecompens }\right)-\left(p_{\text {cand }} \mid E P_{i}=\text { esame }\right) \mid \text { gvtint }=\text { low }\right)= \\
& \quad\left(\left(p_{\text {cand }} \mid E P_{i}=\text { ecompens }\right)-\left(p_{\text {cand }} \mid E P_{i}=\text { esame }\right) \mid \text { gvtint }=\text { high }\right) \\
& H_{a}:\left(\left(p_{\text {cand }} \mid E P_{i}=\text { ecompens }\right)-\left(p_{\text {cand }} \mid E P_{i}=\text { esame }\right) \mid \text { gvtint }=\text { low }\right)< \\
& \quad\left(\left(p_{\text {cand }} \mid E P_{i}=\text { ecompens }\right)-\left(p_{\text {cand }} \mid E P_{i}=\text { esame }\right) \mid \text { gvtint }=\text { high }\right)
\end{aligned}
$$

3.

$$
\begin{aligned}
& H_{0}:\left(\left(p_{\text {cand }} \mid E P_{i}=\text { ecompet }\right)-\left(p_{\text {cand }} \mid E P_{i}=\text { esame }\right) \mid \text { gvtint }=\text { low }\right) \\
& \quad\left(\left(p_{\text {cand }} \mid E P_{i}=\text { ecompet }\right)-\left(p_{\text {cand }} \mid E P_{i}=\text { esame }\right) \mid \text { gvtint }=\text { high }\right) \\
& H_{a}:\left(\left(p_{\text {cand }} \mid E P_{i}=\text { ecompet }\right)-\left(p_{\text {cand }} \mid E P_{i}=\text { esame }\right) \mid \text { gvtint }=\text { low }\right)< \\
& \quad\left(\left(p_{\text {cand }} \mid E P_{i}=\text { ecompet }\right)-\left(p_{\text {cand }} \mid E P_{i}=\text { esame }\right) \mid \text { gvtint }=\text { high }\right)
\end{aligned}
$$

Similarly, we expect the CAMCE for continuation of the energy transition, as well as compensation and competitiveness measures to be larger for individuals who prefer a high degree of redistribution $($ gvtred $=$ high $)$ :

4.

$$
\begin{gathered}
H_{0}:\left(\left(p_{\text {cand }} \mid E P_{i}=\text { esame }\right)-\left(p_{\text {cand }} \mid E P_{i}=\text { eslow }\right) \mid \text { gvtred }=\text { low }\right)= \\
\quad\left(\left(p_{\text {cand }} \mid E P_{i}=\text { esame }\right)-\left(p_{\text {cand }} \mid E P_{i}=\text { eslow }\right) \mid \text { gvtred }=\text { high }\right) \\
H_{a}:\left(\left(p_{\text {cand }} \mid E P_{i}=\text { esame }\right)-\left(p_{\text {cand }} \mid E P_{i}=\text { eslow }\right) \mid \text { gvtred }=\text { low }\right)< \\
\left(\left(p_{\text {cand }} \mid E P_{i}=\text { esame }\right)-\left(p_{\text {cand }} \mid E P_{i}=\text { eslow }\right) \mid \text { gvtred }=\text { high }\right)
\end{gathered}
$$

5.

$$
\begin{gathered}
H_{0}:\left(\left(p_{\text {cand }} \mid E P_{i}=\text { ecompens }\right)-\left(p_{\text {cand }} \mid E P_{i}=\text { esame }\right) \mid \text { gvtred }=\text { low }\right) \\
\quad\left(\left(p_{\text {cand }} \mid E P_{i}=\text { ecompens }\right)-\left(p_{\text {cand }} \mid E P_{i}=\text { esame }\right) \mid \text { gvtred }=\text { high }\right) \\
H_{a}:\left(\left(p_{\text {cand }} \mid E P_{i}=\text { ecompens }\right)-\left(p_{\text {cand }} \mid E P_{i}=\text { esame }\right) \mid \text { gvtred }=\text { low }\right)< \\
\quad\left(\left(p_{\text {cand }} \mid E P_{i}=\text { ecompens }\right)-\left(p_{\text {cand }} \mid E P_{i}=\text { esame }\right) \mid \text { gvtred }=\text { high }\right)
\end{gathered}
$$

6.

$$
\begin{aligned}
& H_{0}:\left(\left(p_{\text {cand }} \mid E P_{i}=\text { ecompet }\right)-\left(p_{\text {cand }} \mid E P_{i}=\text { esame }\right) \mid \text { gvtred }=\text { low }\right) \\
& \quad\left(\left(p_{\text {cand }} \mid E P_{i}=\text { ecompet }\right)-\left(p_{\text {cand }} \mid E P_{i}=\text { esame }\right) \mid \text { gvtred }=\text { high }\right) \\
& H_{a}:\left(\left(p_{\text {cand }} \mid E P_{i}=\text { ecompet }\right)-\left(p_{\text {cand }} \mid E P_{i}=\text { esame }\right) \mid \text { gvtred }=\text { low }\right)< \\
& \quad\left(\left(p_{\text {cand }} \mid E P_{i}=\text { ecompet }\right)-\left(p_{\text {cand }} \mid E P_{i}=\text { esame }\right) \mid \text { gvtred }=\text { high }\right)
\end{aligned}
$$

In addition, we expect the CAMCE for continuation of the energy transition, as well as compensation and competitiveness measures, to be larger for individuals who indicate that they are left-wing and lower for individuals who indicate that they are right-wing: 
7.

$$
\begin{array}{r}
H_{0}:\left(\left(p_{\text {cand }} \mid E P_{i}=\text { esame }\right)-\left(p_{\text {cand }} \mid E P_{i}=\text { eslow }\right) \mid l-r=r i g h t\right) \\
\quad\left(\left(p_{\text {cand }} \mid E P_{i}=\text { esame }\right)-\left(p_{\text {cand }} \mid E P_{i}=\text { eslow }\right) \mid l-r=\text { left }\right) \\
H_{a}:\left(\left(p_{\text {cand }} \mid E P_{i}=\text { esame }\right)-\left(p_{\text {cand }} \mid E P_{i}=\text { eslow }\right) \mid l-r=\text { right }\right)< \\
\quad\left(\left(p_{\text {cand }} \mid E P_{i}=\text { esame }\right)-\left(p_{\text {cand }} \mid E P_{i}=\text { eslow }\right) \mid l-r=\text { left }\right)
\end{array}
$$

8.

$$
\begin{aligned}
& H_{0}:\left(\left(p_{\text {cand }} \mid E P_{i}=\text { ecompens }\right)-\left(p_{\text {cand }} \mid E P_{i}=\text { esame }\right) \mid l-r=\text { right }\right)= \\
& \left(\left(p_{\text {cand }} \mid E P_{i}=\text { ecompens }\right)-\left(p_{\text {cand }} \mid E P_{i}=\text { esame }\right) \mid l-r=\text { left }\right) \\
& H_{a}:\left(\left(p_{\text {cand }} \mid E P_{i}=\text { ecompens }\right)-\left(p_{\text {cand }} \mid E P_{i}=\text { esame }\right) \mid l-r=r i g h t\right)< \\
& \left(\left(p_{\text {cand }} \mid E P_{i}=\text { ecompens }\right)-\left(p_{\text {cand }} \mid E P_{i}=\text { esame }\right) \mid l-r=\text { left }\right)
\end{aligned}
$$

9.

$$
\begin{aligned}
& H_{0}:\left(\left(p_{\text {cand }} \mid E P_{i}=\text { ecompet }\right)-\left(p_{\text {cand }} \mid E P_{i}=\text { esame }\right) \mid l-r=\text { right }\right)= \\
& \left(\left(p_{\text {cand }} \mid E P_{i}=\text { ecompet }\right)-\left(p_{\text {cand }} \mid E P_{i}=\text { esame }\right) \mid l-r=\text { left }\right) \\
& H_{a}:\left(\left(p_{\text {cand }} \mid E P_{i}=\text { ecompet }\right)-\left(p_{\text {cand }} \mid E P_{i}=\text { esame }\right) \mid l-r=\text { right }\right)< \\
& \left(\left(p_{\text {cand }} \mid E P_{i}=\text { ecompet }\right)-\left(p_{\text {cand }} \mid E P_{i}=\text { esame }\right) \mid l-r=\text { left }\right)
\end{aligned}
$$

Further, we expect the CAMCE for continuation of the energy transition, as well as compensation and competitiveness measures, to be larger for individuals who indicate that they trust the government (govtrust=high):

10.

$$
\begin{aligned}
& H_{0}:\left(\left(p_{\text {cand }} \mid E P_{i}=\text { esame }\right)-\left(p_{\text {cand }} \mid E P_{i}=\text { eslow }\right) \mid \text { govtrust }=\text { low }\right) \\
& \quad\left(\left(p_{\text {cand }} \mid E P_{i}=\text { esame }\right)-\left(p_{\text {cand }} \mid E P_{i}=\text { eslow }\right) \mid \text { govtrust }=\text { high }\right) \\
& H_{a}:\left(\left(p_{\text {cand }} \mid E P_{i}=\text { esame }\right)-\left(p_{\text {cand }} \mid E P_{i}=\text { eslow }\right) \mid \text { govtrust }=\text { low }\right)< \\
& \quad\left(\left(p_{\text {cand }} \mid E P_{i}=\text { esame }\right)-\left(p_{\text {cand }} \mid E P_{i}=\text { eslow }\right) \mid \text { govtrust }=\text { high }\right)
\end{aligned}
$$

11.

$$
\begin{aligned}
& H_{0}:\left(\left(p_{\text {cand }} \mid E P_{i}=\text { ecompens }\right)-\left(p_{\text {cand }} \mid E P_{i}=\text { esame }\right) \mid \text { govtrust }=\text { low }\right)= \\
& \quad\left(\left(p_{\text {cand }} \mid E P_{i}=\text { ecompens }\right)-\left(p_{\text {cand }} \mid E P_{i}=\text { esame }\right) \mid \text { govtrust }=\text { high }\right) \\
& H_{a}:\left(\left(p_{\text {cand }} \mid E P_{i}=\text { ecompens }\right)-\left(p_{\text {cand }} \mid E P_{i}=\text { esame }\right) \mid \text { govtrust }=\text { low }\right)< \\
& \quad\left(\left(p_{\text {cand }} \mid E P_{i}=\text { ecompens }\right)-\left(p_{\text {cand }} \mid E P_{i}=\text { esame }\right) \mid \text { govtrust }=\text { high }\right)
\end{aligned}
$$

12.

$$
\begin{gathered}
H_{0}:\left(\left(p_{\text {cand }} \mid E P_{i}=\text { ecompet }\right)-\left(p_{\text {cand }} \mid E P_{i}=\text { esame }\right) \mid \text { govtrust }=\text { low }\right) \\
\quad\left(\left(p_{\text {cand }} \mid E P_{i}=\text { ecompet }\right)-\left(p_{\text {cand }} \mid E P_{i}=\text { esame }\right) \mid \text { govtrust }=\text { high }\right) \\
H_{a}:\left(\left(p_{\text {cand }} \mid E P_{i}=\text { ecompet }\right)-\left(p_{\text {cand }} \mid E P_{i}=\text { esame }\right) \mid \text { govtrust }=\text { low }\right)< \\
\quad\left(\left(p_{\text {cand }} \mid E P_{i}=\text { ecompet }\right)-\left(p_{\text {cand }} \mid E P_{i}=\text { esame }\right) \mid \text { govtrust }=\text { high }\right)
\end{gathered}
$$


Lastly, we expect that the CAMCE of support for the energy transition is smaller for respondents who are employed in sectors that emit more CO2 $(\mathrm{CO} 2 \mathrm{sec}=$ high $)$, compared to the CAMCE for respondents who are employed in sectors that emit less $\mathrm{CO} 2(\mathrm{CO} 2 \mathrm{sec}=\mathrm{low})$.

13.

$$
\begin{aligned}
& H_{0}:\left(\left(p_{\text {cand }} \mid E P_{i}=\text { esame }\right)-\left(p_{\text {cand }} \mid E P_{i}=\text { eslow }\right) \mid C O 2 s e c=\text { high }\right)= \\
& \left.\left(\left(p_{\text {cand }} \mid E P_{i}=\text { esame }\right)\right)-\left(p_{\text {cand }} \mid E P_{i}=\text { eslow }\right) \mid C O 2 s e c=\text { low }\right) \\
& H_{a}:\left(\left(p_{\text {cand }} \mid E P_{i}=\text { esame }\right)-\left(p_{\text {cand }} \mid E P_{i}=\text { eslow }\right) \mid C O 2 s e c=h i g h\right)< \\
& \left(\left(p_{\text {cand }} \mid E P_{i}=\text { esame }\right)-\left(p_{\text {cand }} \mid E P_{i}=\text { eslow }\right) \mid C O 2 s e c=l o w\right)
\end{aligned}
$$

\subsection{Analysis Experiment 2}

The second experiment has two outcome questions: General support for a complete coal exit and the "ideal" year in which to exit. Out of these, we create four alternative outcome variables that

we use to estimate average treatment effects (ATEs) and conditional average treatment effects (CATEs):

1. Year earlier than max (yem): continuous variable calculated as (2050 - ideal year indicated)

2. Year earlier or later than currently anticipated date of policy exit (2038) (yb): binary variable with value 1 of ideal year indicated is before 2038, 0 otherwise

3. General support (gs): continous variable that takes values $0-5$, where 0 indicates absolutely no support for a full coal exit, and 5 indicates complete support for a full coal exit

4. Binary General support (bgs): Binary variable that takes the value 1 if respondents express complete support or support for a full coal exit, and 0 if respondents express no support or absolutely no support for a full coal exit

For all these variables, a higher value indicates increased support for a full and speedy coal exit. To preserve space, we will use "y" as a placeholder for all four outcome variables in the hypotheses specified below.

All hypotheses specified below will be analysed using OLS regression.

We expect that all compensation treatments should increase support for an early coal exit. We thus specify null hypotheses with one-sided alternative hypotheses. For all $T \in\{T 1, T 2, T 3, T 4\}$, we expect:

1.

$$
\begin{aligned}
& H_{0}:\left(y \mid C V_{i}=T\right)=\left(y \mid C V_{i}=C\right) \\
& H_{a}:\left(y \mid C V_{i}=T\right)>\left(y \mid C V_{i}=C\right)
\end{aligned}
$$

We have no strong priors about the difference in treatment effects of different forms of compensation. Therefore, we test the differences between the compensation treatment effects using two-sided alternative hypotheses. For all $T_{a}, T_{b} \in\{T 1, T 2, T 3, T 4\}$ such that $T_{a} \neq T_{b}$ : 
2 .

$$
\begin{aligned}
& H_{0}:\left(y \mid C V_{i}=T_{a}\right)=\left(y \mid C V_{i}=T_{b}\right) \\
& H_{a}:\left(y \mid C V_{i}=T_{a}\right) \neq\left(y \mid C V_{i}=T_{b}\right)
\end{aligned}
$$

\subsubsection{Heterogeneity Analysis Experiment 2}

We are further interested in the difference in treatment effects between a number of subgroups. For our heterogenetiy probes we use the same sets of subgroups listed for experiment 1.

To test heterogeneity, we run all analyses on the subset of individuals that fall within each listed subgroup. Further, we test the difference in conditional average treatment effects by running OLS regressions that interact the treatment assignment with subgroup characteristics. For this set of regressions, we use heteroskedasticity-robust standard errors. For variables that measure attributes on a scale with more than two levels, e.g. trust in government, we run two analyses for robustness: First, we recode the variable into a binary indicator of high-low and use this binary variable to analyse sub-samples and run regressions with interaction effects. Second, we also run regressions with interaction using the original variable with more than two levels.

For most of the subgroup comparisons, we have no strong priors on the direction of the difference in CATE. We thus employ two-sided alternative hypotheses unless otherwise specified.

Similar to our expectations in experiment 1, we expect that the CATE of any compensation treatment will be larger for individuals who prefer high government intervention. We also expect the CATE of any compensation treatment to be larger for those who prefer high government redistribution, those who have high trust in the government, and individuals who are politically left-wing.

Thus, for all $T \in\{T 1, T 2, T 3, T 4\}$, we expect:

1.

$$
\begin{array}{cc}
H_{0}: \quad\left(\left(y \mid C V_{i}=T\right)-\left(y \mid C V_{i}=C\right) \mid \text { gvtint }=\text { low }\right) \quad= \\
& \left(\left(y \mid C V_{i}=T\right)-\left(y \mid C V_{i}=C\right) \mid \text { gvtint = high }\right) \\
H_{a}: \quad\left(\left(y \mid C V_{i}=T\right)-\left(y \mid C V_{i}=C\right) \mid \text { gvtint = low }\right)< \\
\left(\left(y \mid C V_{i}=T\right)-\left(y \mid C V_{i}=C\right) \mid \text { gvtint = high }\right)
\end{array}
$$

2.

$$
\begin{array}{cc}
H_{0}: \quad\left(\left(y \mid C V_{i}=T\right)-\left(y \mid C V_{i}=C\right) \mid \text { gvtred }=\text { low }\right) \quad= \\
\left(\left(y \mid C V_{i}=T\right)-\left(y \mid C V_{i}=C\right) \mid \text { gvtred = high }\right) \\
H_{a}: \quad\left(\left(y \mid C V_{i}=T\right)-\left(y \mid C V_{i}=C\right) \mid \text { gvtred = low }\right)< \\
\left(\left(y \mid C V_{i}=T\right)-\left(y \mid C V_{i}=C\right) \mid \text { gvtred = high }\right)
\end{array}
$$


3.

$$
\begin{array}{cc}
H_{0}: \quad\left(\left(y \mid C V_{i}=T\right)-\left(y \mid C V_{i}=C\right) \mid l-r=r i g h t\right)= \\
\left(\left(y \mid C V_{i}=T\right)-\left(y \mid C V_{i}=C\right) \mid l-r=\text { left }\right) \\
H_{a}: \quad\left(\left(y \mid C V_{i}=T\right)-\left(y \mid C V_{i}=C\right) \mid l-r=\text { right }\right)< \\
\left(\left(y \mid C V_{i}=T\right)-\left(y \mid C V_{i}=C\right) \mid l-r=\text { left }\right)
\end{array}
$$

4.

$$
\begin{array}{cc}
H_{0}: \quad\left(\left(y \mid C V_{i}=T\right)-\left(y \mid C V_{i}=C\right) \mid \text { govtrust }=\text { low }\right) \quad= \\
& \left(\left(y \mid C V_{i}=T\right)-\left(y \mid C V_{i}=C\right) \mid \text { govtrust = high }\right) \\
H_{a}: \quad\left(\left(y \mid C V_{i}=T\right)-\left(y \mid C V_{i}=C\right) \mid \text { govtrust }=\text { low }\right)< \\
\\
\left(\left(y \mid C V_{i}=T\right)-\left(y \mid C V_{i}=C\right) \mid \text { govtrust = high }\right)
\end{array}
$$

Further, since three of Germany's four current coal regions are located in Eastern Germany, we further expect that the CATE of regional compensation (T4) should be larger for the voters of parties with strong regional support in the East (AfD and die Linke). Voters for other parties will be summarized here as "other". We also expect the effect to be larger for those who switched their vote from a different party in 2017 to the AfD in 2021. Thus, our hypotheses are as follows:

5.

$$
\begin{aligned}
& H_{0}: \quad\left(\left(y \mid C V_{i}=T 4\right)-\left(y \mid C V_{i}=C\right) \mid \text { party }=\text { other }\right)= \\
&\left(\left(y \mid C V_{i}=T 4\right)-\left(y \mid C V_{i}=C\right) \mid \text { party }=\text { AfD }\right) \\
& H_{a}: \quad\left(\left(y \mid C V_{i}=T 4\right)-\left(y \mid C V_{i}=C\right) \mid \text { party }=\text { other }\right)< \\
& \\
&\left(\left(y \mid C V_{i}=T 4\right)-\left(y \mid C V_{i}=C\right) \mid \text { party }=\text { AfD }\right)
\end{aligned}
$$

6.

$$
\begin{array}{cl}
H_{0}: \quad\left(\left(y \mid C V_{i}=T 4\right)-\left(y \mid C V_{i}=C\right) \mid \text { party }=\text { other }\right) \quad= \\
& \left(\left(y \mid C V_{i}=T 4\right)-\left(y \mid C V_{i}=C\right) \mid \text { party }=\text { Linke }\right) \\
H_{a}: \quad\left(\left(y \mid C V_{i}=T 4\right)-\left(y \mid C V_{i}=C\right) \mid \text { party }=\text { other }\right)< \\
\\
\left(\left(y \mid C V_{i}=T 4\right)-\left(y \mid C V_{i}=C\right) \mid \text { party }=\text { Linke }\right)
\end{array}
$$

7.

$$
\begin{array}{cc}
H_{0}: \quad\left(\left(y \mid C V_{i}=T 4\right)-\left(y \mid C V_{i}=C\right) \mid \text { AfD Dwitch }=n o\right) & = \\
& \left(\left(y \mid C V_{i}=T 4\right)-\left(y \mid C V_{i}=C\right) \mid \text { AfDswitch }=y e s\right) \\
H_{a}: \quad\left(\left(y \mid C V_{i}=T 4\right)-\left(y \mid C V_{i}=C\right) \mid \text { AfDswitch }=\text { no }\right) & < \\
& \left(\left(y \mid C V_{i}=T 4\right)-\left(y \mid C V_{i}=C\right) \mid \text { AfDswitch =yes }\right)
\end{array}
$$




\subsection{Analysis Experiment 3}

The outcome variable for the third experiment is respondents' choice between the two policy plans they were presented with. As in experiment 1 , we calculate the average marginal component effects (AMCEs) of all the attributes in our conjoint experiment. These quantities provide each attribute's estimated effect on the probability of choosing a plan.

As before, we first reshape the data. Respondents are presented with five conjoint tables that each compare 2 plans. We code each choice as a binary variable for each of the plans ( 1 if plan was chosen, 0 if plan was not chosen) and create a long-form dataset with $5^{*} 2^{*} n$ rows, where each row represents an individual-plan-choice. To account for the fact that responses from the same individuals likely have correlated error terms, we cluster all standard errors at the respondent-level.

For our analysis, we then set the following default categories:

- Cost: cl (150 Euros per Year)

- Effectiveness: el (estimated CO2 reduction of $25 \%$ by 2030)

- Compensation for Consumers: cnc (no change)

- Measures to Ensure Competitiveness: ctnc (no change)

As we combine the conjoint table with a vignette experiment, we first specify our hypotheses regarding AMCEs in the conjoint for just the control group. We then specify and test expected differences in AMCEs by treatment group.

Our first clear expectation is that support for a plan decreases as costs increase. We calculate the AMCEs of moving from the low cost plan to a higher cost plan for all higher cost plans $(\mathrm{cml}, \mathrm{cmh}$, ch). For brevity, we use "chigher" as a place holder for all higher cost plans. Further, we calculate the AMCEs of moving to the next more costly option:

1.

$$
\begin{aligned}
& H_{0}:\left(p_{\text {plan }} \mid C=c l\right)=\left(p_{\text {plan }} \mid C=\text { chigher }\right) \\
& H_{a}:\left(p_{\text {plan }} \mid C=c l\right)>\left(p_{\text {plan }} \mid C=\text { chigher }\right)
\end{aligned}
$$

2 .

$$
\begin{aligned}
& \left.H_{0}:\left(p_{\text {plan }} \mid C=c m l\right)=\left(p_{\text {plan }} \mid C=c m h\right)\right) \\
& \left.H_{a}:\left(p_{\text {plan }} \mid C=c m l\right)>\left(p_{\text {plan }} \mid C=c m h\right)\right)
\end{aligned}
$$

3.

$$
\begin{aligned}
& \left.H_{0}:\left(p_{\text {plan }} \mid C=c m h\right)=\left(p_{\text {plan }} \mid C=c h\right)\right) \\
& \left.H_{a}:\left(p_{\text {plan }} \mid C=c m h\right)>\left(p_{\text {plan }} \mid C=c h\right)\right)
\end{aligned}
$$

In addition, we also replicate the analyses using a binary indicator of higher or lower cost (clow if $\mathrm{C}=\mathrm{cl}$ or $\mathrm{cml}$, and chigh if $\mathrm{C}=\mathrm{cmh}$ or $\mathrm{ch}$ ):

4.

$$
\begin{aligned}
& \left.H_{0}:\left(p_{\text {plan }} \mid C=\text { clow }\right)=\left(p_{\text {plan }} \mid C=\text { chigh }\right)\right) \\
& \left.H_{a}:\left(p_{\text {plan }} \mid C=\text { clow }\right)>\left(p_{\text {plan }} \mid C=\text { chigh }\right)\right)
\end{aligned}
$$


Further, we expect that competitiveness and compensation measures should increase support for a policy plan.

5.

$$
\begin{aligned}
& \left.H_{0}:\left(p_{\text {plan }} \mid C S=\text { clls }\right)=\left(p_{\text {plan }} \mid C S=c n c\right)\right) \\
& \left.H_{a}:\left(p_{\text {plan }} \mid C S=\text { clls }\right)>\left(p_{\text {plan }} \mid C S=c n c\right)\right)
\end{aligned}
$$

6.

$$
\begin{aligned}
& \left.H_{0}:\left(p_{\text {plan }} \mid C S=\text { chls }\right)=\left(p_{\text {plan }} \mid C S=c n c\right)\right) \\
& \left.H_{a}:\left(p_{\text {plan }} \mid C S=\text { chls }\right)>\left(p_{\text {plan }} \mid C S=c n c\right)\right)
\end{aligned}
$$

7.

$$
\begin{aligned}
& \left.H_{0}:\left(p_{\text {plan }} \mid C S=c l p\right)=\left(p_{\text {plan }} \mid C S=c n c\right)\right) \\
& \left.H_{a}:\left(p_{\text {plan }} \mid C S=c l p\right)>\left(p_{\text {plan }} \mid C S=c n c\right)\right)
\end{aligned}
$$

8.

$$
\begin{aligned}
& \left.H_{0}:\left(p_{\text {plan }} \mid C S=\operatorname{chp}\right)=\left(p_{\text {plan }} \mid C S=c n c\right)\right) \\
& \left.H_{a}:\left(p_{\text {plan }} \mid C S=\operatorname{chp}\right)>\left(p_{\text {plan }} \mid C S=c n c\right)\right)
\end{aligned}
$$

9.

$$
\begin{aligned}
& \left.H_{0}:\left(p_{\text {plan }} \mid C T=c b t\right)=\left(p_{\text {plan }} \mid C T=c t n c\right)\right) \\
& \left.H_{a}:\left(p_{\text {plan }} \mid C T=c b t\right)>\left(p_{\text {plan }} \mid C T=c t n c\right)\right)
\end{aligned}
$$

10.

$$
\begin{aligned}
& \left.H_{0}:\left(p_{\text {plan }} \mid C T=p t a\right)=\left(p_{\text {plan }} \mid C T=c t n c\right)\right) \\
& \left.H_{a}:\left(p_{\text {plan }} \mid C T=p t a\right)>\left(p_{\text {plan }} \mid C T=c t n c\right)\right)
\end{aligned}
$$

Moreover, support should be higher for plans with high compensation than for plans with low levels of compensation.

11.

$$
\begin{aligned}
& \left.H_{0}:\left(p_{\text {plan }} \mid C S=\text { chls }\right)=\left(p_{\text {plan }} \mid C S=\text { clls }\right)\right) \\
& \left.H_{a}:\left(p_{\text {plan }} \mid C S=\text { chls }\right)>\left(p_{\text {plan }} \mid C S=\text { clls }\right)\right)
\end{aligned}
$$

12.

$$
\begin{aligned}
& \left.H_{0}:\left(p_{\text {plan }} \mid C S=c h p\right)=\left(p_{\text {plan }} \mid C S=c l p\right)\right) \\
& \left.H_{a}:\left(p_{\text {plan }} \mid C S=c h p\right)>\left(p_{\text {plan }} \mid C S=c l p\right)\right)
\end{aligned}
$$


We have no strong priors on whether individuals should prefer plans that pay progressive or lump sum compensation. We also have no strong priors on which competitiveness treatment should lead to higher support. We thus test the difference between these treatments using two-sided alternative hypotheses.

13.

$$
\begin{aligned}
& \left.H_{0}:\left(p_{\text {plan }} \mid C S=c l l s\right)=\left(p_{\text {plan }} \mid C S=c l p\right)\right) \\
& \left.H_{a}:\left(p_{\text {plan }} \mid C S=c l l s\right) \neq\left(p_{\text {plan }} \mid C S=c l p\right)\right)
\end{aligned}
$$

14 .

$$
\begin{aligned}
& \left.H_{0}:\left(p_{\text {plan }} \mid C S=\text { chls }\right) \quad\left(p_{\text {plan }} \mid C S=\operatorname{chp}\right)\right) \\
& \left.H_{a}:\left(p_{\text {plan }} \mid C S=\text { chls }\right) \neq\left(p_{\text {plan }} \mid C S=\text { chp }\right)\right)
\end{aligned}
$$

15.

$$
\begin{aligned}
& \left.H_{0}:\left(p_{\text {plan }} \mid C T=c b t\right)=\left(p_{\text {plan }} \mid C T=p t a\right)\right) \\
& \left.H_{a}:\left(p_{\text {plan }} \mid C T=c b t\right) \neq\left(p_{\text {plan }} \mid C T=p t a\right)\right)
\end{aligned}
$$

Lastly, we expect that individuals prefer more effective plans:

16.

$$
\begin{aligned}
& \left.H_{0}:\left(p_{\text {plan }} \mid E=e h\right)=\left(p_{\text {plan }} \mid E=e l\right)\right) \\
& \left.H_{a}:\left(p_{\text {plan }} \mid E=e h\right)>\left(p_{\text {plan }} \mid E=e l\right)\right)
\end{aligned}
$$

\subsubsection{Interactions between Conjoint Attributes Experiment 3}

We are also interested in the Average Interaction Effects (AIEs) between specific attributes. To test these, we run OLS regressions that contain interaction terms between the attributes of interest.

First, we expect that more compensation should lower the negative effect cost has on support. For brevity, we summarize the hypotheses as one set of hypotheses where we move from lower to higher cost (standing in for: $\mathrm{cl} \rightarrow \mathrm{cml}, \mathrm{cl} \rightarrow \mathrm{cmh}, \mathrm{cl} \rightarrow \mathrm{ch}, \mathrm{cml} \rightarrow \mathrm{cmh}, \mathrm{cml} \rightarrow \mathrm{ch}, \mathrm{cmh} \rightarrow \mathrm{ch}$, or the binary variable clow $\rightarrow$ chigh) and where we move from lower to higher compensation (standing in for: $\mathrm{cnc} \rightarrow$ clls, cnc $\rightarrow$ chls, cnc $\rightarrow$ clp, cnc $\rightarrow$ chp, clp $\rightarrow$ chp, clls $\rightarrow$ chls).

17.

$$
\begin{array}{cc}
\left.H_{0}: \quad\left(p_{\text {plan }} \mid C=\text { lower }\right)-\left(p_{\text {plan }} \mid C=\text { higher }\right) \mid C S=\text { lower }\right) & = \\
& \left(\left(p_{\text {plan }} \mid C=\text { lower }\right)-\left(p_{\text {plan }} \mid C=\text { higher }\right) \mid C S=\text { higher }\right) \\
H_{a}: \quad\left(\left(p_{\text {plan }} \mid C=\text { lower }\right)-\left(p_{\text {plan }} \mid C=\text { higher }\right) \mid C S=\text { lower }\right) \\
\left(\left(p_{\text {plan }} \mid C=\text { lower }\right)-\left(p_{\text {plan }} \mid C=\text { higher }\right) \mid C S=\text { higher }\right)
\end{array}>
$$


Second, we expect that more measures that ensure competition should lower the negative effect cost has on support for a plan. For brevity, we summarize the hypotheses as one set of hypotheses where we move from lower to higher cost (standing in for: $\mathrm{cl} \rightarrow \mathrm{cml}, \mathrm{cl} \rightarrow \mathrm{cmh}, \mathrm{cl} \rightarrow \mathrm{ch}, \mathrm{cml} \rightarrow$ $\mathrm{cmh}, \mathrm{cml} \rightarrow \mathrm{ch}, \mathrm{cmh} \rightarrow \mathrm{ch}$, or the binary variable clow $\rightarrow$ chigh) and where we move from less to more competition measures (standing in for: ctnc $\rightarrow$ cbt, ctnc $\rightarrow$ pta).

18.

$$
\begin{array}{cc}
H_{0}: \quad\left(\left(p_{\text {plan }} \mid C=\text { lower }\right)-\left(p_{\text {plan }} \mid C=\text { higher }\right) \mid C T=\text { less }\right) & = \\
& \left(\left(p_{\text {plan }} \mid C=\text { lower }\right)-\left(p_{\text {plan }} \mid C=\text { higher }\right) \mid C T=\text { more }\right) \\
H_{a}: \quad\left(\left(p_{\text {plan }} \mid C=\text { lower }\right)-\left(p_{\text {plan }} \mid C=\text { higher }\right) \mid C T=\text { less }\right) \\
\left(\left(p_{\text {plan }} \mid C=\text { lower }\right)-\left(p_{\text {plan }} \mid C=\text { higher }\right) \mid C T=\text { more }\right)
\end{array}>
$$

\subsubsection{Expected Effects of Vignette Texts, Experiment 3}

We compute and compare the AMCEs for each of the vignette treatment groups (control, treatment 1 , treatment 2). To do so, we run OLS regressions that interact the treatment condition with the conjoint attributes of interest. This effectively allows us to quantify the difference in differences between treatment conditions.

Our expectations are as follows: First, the compensation treatment should diminish the magnitude of the cost variables' AMCEs, relative to the control group. We thus expect the following:

19.

$$
\begin{array}{cc}
H_{0}: & \left(\left(p_{\text {plan }} \mid C=\text { higher }\right)-\left(p_{\text {plan }} \mid C=\text { lower }\right) \mid T=T 1\right)= \\
& \left(\left(p_{\text {plan }} \mid C=\text { higher }\right)-\left(p_{\text {plan }} \mid C=\text { lower }\right) \mid T=C\right) \\
H_{a}: \quad\left(\left(p_{\text {plan }} \mid C=\text { higher }\right)-\left(p_{\text {plan }} \mid C=\text { lower }\right) \mid T=T 1\right)< \\
\left(\left(p_{\text {plan }} \mid C=\text { higher }\right)-\left(p_{\text {plan }} \mid C=\text { lower }\right) \mid T=C\right)
\end{array}
$$

Similarly, the competitiveness treatment may reduce the size of the cost AMCEs:

20 .

$$
\begin{array}{cc}
H_{0}: & \left(\left(p_{\text {plan }} \mid C=\text { higher }\right)-\left(p_{\text {plan }} \mid C=\text { lower }\right) \mid T=T 2\right)= \\
& \left(\left(p_{\text {plan }} \mid C=\text { higher }\right)-\left(p_{\text {plan }} \mid C=\text { lower }\right) \mid T=C\right) \\
H_{a}: \quad\left(\left(p_{\text {plan }} \mid C=\text { higher }\right)-\left(p_{\text {plan }} \mid C=\text { lower }\right) \mid T=T 2\right)< \\
\left(\left(p_{\text {plan }} \mid C=\text { higher }\right)-\left(p_{\text {plan }} \mid C=\text { lower }\right) \mid T=C\right)
\end{array}
$$

Further, we expect that the hypothesized treatment effects of both compensation measures and carbon border taxes should be larger if individuals are primed to pay attention to compensation/carbon border taxes in the vignette experiment. For all compensation measures, we test the hypotheses: 
21.

$$
\begin{array}{cc}
H_{0}: & \left(\left(p_{\text {plan }} \mid C S=\text { higher }\right)-\left(p_{\text {plan }} \mid C S=\text { lower } \mid T=T 1\right)=\right. \\
& \left(\left(p_{\text {plan }} \mid C S=\text { higher }\right)-\left(p_{\text {plan }} \mid C S=\text { lower } \mid T=C\right)\right. \\
H_{a}: \quad\left(\left(p_{\text {plan }} \mid C S=\text { higher }\right)-\left(p_{\text {plan }} \mid C S=\text { lower } \mid T=T 1\right)\right. & > \\
\left(\left(p_{\text {plan }} \mid C S=\text { higher }\right)-\left(p_{\text {plan }} \mid C S=\text { lower } \mid T=C\right)\right.
\end{array}
$$

Further, for all competitiveness measures, we test the hypotheses:

22 .

$$
\begin{array}{cc}
H_{0}: \quad\left(\left(p_{\text {plan }} \mid C T=\text { more }\right)-\left(p_{\text {plan }} \mid C T=\text { less } T=T 2\right)\right. & = \\
& \left(\left(p_{\text {plan }} \mid C T=\text { more }\right)-\left(p_{\text {plan }} \mid C T=\text { less } \mid T=C\right)\right. \\
H_{a}: \quad\left(\left(p_{\text {plan }} \mid C T=\text { more }\right)-\left(p_{\text {plan }} \mid C T=\text { less } \mid T=T 2\right)\right. & > \\
\left(\left(p_{\text {plan }} \mid C T=\text { more }\right)-\left(p_{\text {plan }} \mid C T=\text { less } \mid T=C\right)\right.
\end{array}
$$

\subsubsection{Heterogeneity Analysis Experiment 3}

As with the two preceding experiments, we conduct some heterogeneity probes for experiment 3. For all heterogeneity probes that use variables which measure attributes on a scale with more than two levels, e.g. trust in government, we run two analyses for robustness: First, we recode the variable into a binary indicator of high-low and use this binary variable.

In this experiment, we are particularly interested in the heterogeneity by support for the welfare state, preference for government intervention, left-right orientation, and trust in the government. First, we expect that the conditional average marginal treatment effects of the compensation and competitiveness measures in our conjoint tables are larger for individuals with high trust in the government, support for the welfare state, support for government interventino, and a left-wing orientation. Second, we also run regressions using the original variable with more than two levels. For brevity, we again refer to all changes from less compensation to more and from fewer competitiveness measures to more in one summary expression of the hypotheses:

1.

$$
\begin{array}{cc}
H_{0}: \quad\left(\left(p_{\text {plan }} \mid C S=\text { higher }\right)-\left(p_{\text {plan }} \mid C S=\text { lower }\right) \mid \text { gvtint }=\text { low }\right)= \\
\left(\left(p_{\text {plan }} \mid C S=\text { higher }\right)-\left(p_{\text {plan }} \mid C S=\text { lower }\right) \mid \text { gvtint }=\text { high }\right) \\
H_{a}: \quad\left(\left(p_{\text {plan }} \mid C S=\text { higher }\right)-\left(p_{\text {plan }} \mid C S=\text { lower }\right) \mid \text { gvtint }=\text { low }\right)< \\
\left(\left(p_{\text {plan }} \mid C S=\text { higher }\right)-\left(p_{\text {plan }} \mid C S=\text { lower }\right) \mid \text { gvtint }=\text { high }\right)
\end{array}
$$


2.

$$
\begin{array}{cc}
H_{0}: \quad\left(\left(p_{\text {plan }} \mid C S=\text { higher }\right)-\left(p_{\text {plan }} \mid C S=\text { lower }\right) \mid \text { gvtred }=\text { low }\right) & = \\
& \left(\left(p_{\text {plan }} \mid C S=\text { higher }\right)-\left(p_{\text {plan }} \mid C S=\text { lower }\right) \mid \text { gvtred }=\text { high }\right) \\
H_{a}: \quad\left(\left(p_{\text {plan }} \mid C S=\text { higher }\right)-\left(p_{\text {plan }} \mid C S=\text { lower }\right) \mid \text { gvtred }=\text { low }\right) & < \\
& \left(\left(p_{\text {plan }} \mid C S=\text { higher }\right)-\left(p_{\text {plan }} \mid C S=\text { lower }\right) \mid \text { gvtred }=\text { high }\right)
\end{array}
$$

3.

$$
\begin{array}{cc}
\left.H_{0}: \quad\left(p_{\text {plan }} \mid C S=\text { higher }\right)-\left(p_{\text {plan }} \mid C S=\text { lower }\right) \mid l-r=\text { right }\right)= \\
\left(\left(p_{\text {plan }} \mid C S=\text { higher }\right)-\left(p_{\text {plan }} \mid C S=\text { lower }\right) \mid l-r=\text { left }\right) \\
H_{a}: \quad\left(\left(p_{\text {plan }} \mid C S=\text { higher }\right)-\left(p_{\text {plan }} \mid C S=\text { lower }\right) \mid l-r=\text { right }\right)< \\
\left(\left(p_{\text {plan }} \mid C S=\text { higher }\right)-\left(p_{\text {plan }} \mid C S=\text { lower }\right) \mid l-r=\text { left }\right)
\end{array}
$$

4.

$$
\begin{array}{cc}
H_{0}: \quad\left(\left(p_{\text {plan }} \mid C S=\text { higher }\right)-\left(p_{\text {plan }} \mid C S=\text { lower }\right) \mid \text { govtrust }=\text { low }\right) & = \\
& \left(\left(p_{\text {plan }} \mid C S=\text { higher }\right)-\left(p_{\text {plan }} \mid C S=\text { lower }\right) \mid \text { govtrust }=\text { high }\right) \\
H_{a}: \quad\left(\left(p_{\text {plan }} \mid C S=\text { higher }\right)-\left(p_{\text {plan }} \mid C S=\text { lower }\right) \mid \text { govtrust }=\text { low }\right) & < \\
& \left(\left(p_{\text {plan }} \mid C S=\text { higher }\right)-\left(p_{\text {plan }} \mid C S=\text { lower }\right) \mid \text { govtrust }=\text { high }\right)
\end{array}
$$

5.

$$
\begin{array}{cc}
H_{0}: \quad\left(\left(p_{\text {plan }} \mid C T=\text { more }\right)-\left(p_{\text {plan }} \mid C T=\text { less }\right) \mid \text { gvtint }=\text { low }\right) \quad= \\
\left(\left(p_{\text {plan }} \mid C T=\text { more }\right)-\left(p_{\text {plan }} \mid C T=\text { less }\right) \mid \text { gvtint }=\text { high }\right) \\
H_{a}: \quad\left(\left(p_{\text {plan }} \mid C T=\text { more }\right)-\left(p_{\text {plan }} \mid C T=\text { less }\right) \mid \text { gvtint }=\text { low }\right) \quad< \\
\left(\left(p_{\text {plan }} \mid C T=\text { more }\right)-\left(p_{\text {plan }} \mid C T=\text { less }\right) \mid \text { gvtint }=\text { high }\right)
\end{array}
$$

6.

$$
\begin{array}{cc}
H_{0}: \quad\left(\left(p_{\text {plan }} \mid C T=\text { more }\right)-\left(p_{\text {plan }} \mid C T=\text { less }\right) \mid \text { gvtred }=\text { low }\right) & = \\
& \left(\left(p_{\text {plan }} \mid C T=\text { more }\right)-\left(p_{\text {plan }} \mid C T=\text { less }\right) \mid \text { gvtred }=\text { high }\right) \\
H_{a}: \quad\left(\left(p_{\text {plan }} \mid C T=\text { more }\right)-\left(p_{\text {plan }} \mid C T=\text { less }\right) \mid \text { gvtred }=\text { low }\right) & < \\
\left(\left(p_{\text {plan }} \mid C T=\text { more }\right)-\left(p_{\text {plan }} \mid C T=\text { less }\right) \mid \text { gvtred }=\text { high }\right)
\end{array}
$$

7.

$$
\begin{array}{cc}
\left.H_{0}: \quad\left(p_{\text {plan }} \mid C T=\text { more }\right)-\left(p_{\text {plan }} \mid C T=\text { less }\right) \mid l-r=\text { right }\right) & = \\
& \left(\left(p_{\text {plan }} \mid C T=\text { more }\right)-\left(p_{\text {plan }} \mid C T=\text { less }\right) \mid l-r=\text { left }\right) \\
H_{a}: \quad\left(\left(p_{\text {plan }} \mid C T=\text { more }\right)-\left(p_{\text {plan }} \mid C T=\text { less }\right) \mid l-r=\text { right }\right)< \\
\left(\left(p_{\text {plan }} \mid C T=\text { more }\right)-\left(p_{\text {plan }} \mid C T=\text { less }\right) \mid l-r=\text { left }\right)
\end{array}
$$


8.

$$
\begin{array}{cc}
H_{0}: \quad\left(\left(p_{\text {plan }} \mid C T=\text { more }\right)-\left(p_{\text {plan }} \mid C T=\text { less }\right) \mid \text { govtrust }=\text { low }\right) & = \\
& \left(\left(p_{\text {plan }} \mid C T=\text { more }\right)-\left(p_{\text {plan }} \mid C T=\text { less }\right) \mid \text { govtrust }=\text { high }\right) \\
H_{a}: \quad\left(\left(p_{\text {plan }} \mid C T=\text { more }\right)-\left(p_{\text {plan }} \mid C T=\text { less }\right) \mid \text { govtrust }=\text { low }\right)< & < \\
& \left(\left(p_{\text {plan }} \mid C T=\text { more }\right)-\left(p_{\text {plan }} \mid C T=\text { less }\right) \mid \text { govtrust }=\text { high }\right)
\end{array}
$$

In addition, we expect that individuals who are more exposed to the international market through their employment (employer exports, is import-competing, or engages in FDI) should respond more strongly to competition measures in the conjoint table:

9.

$$
\begin{array}{cc}
\left.H_{0}: \quad\left(p_{\text {plan }} \mid C T=\text { more }\right)-\left(p_{\text {plan }} \mid C T=\text { less }\right) \mid \text { exporter }=\text { yes }\right) & = \\
& \left(\left(p_{\text {plan }} \mid C T=\text { more }\right)-\left(p_{\text {plan }} \mid C T=\text { less }\right) \mid \text { exporter }=\text { no }\right) \\
H_{a}: \quad\left(\left(p_{\text {plan }} \mid C T=\text { more }\right)-\left(p_{\text {plan }} \mid C T=\text { less }\right) \mid \text { exporter }=\text { yes }\right) & > \\
\left(\left(p_{\text {plan }} \mid C T=\text { more }\right)-\left(p_{\text {plan }} \mid C T=\text { less }\right) \mid \text { exporter }=\text { no }\right)
\end{array}
$$

10.

$$
\begin{gathered}
H_{0}:\left(\left(p_{\text {plan }} \mid C T=\text { more }\right)-\left(p_{\text {plan }} \mid C T=\text { less }\right) \mid \text { importcomp }=\text { yes }\right)= \\
\left(\left(p_{\text {plan }} \mid C T=\text { more }\right)-\left(p_{\text {plan }} \mid C T=\text { less }\right) \mid \text { importer }=\text { no }\right) \\
H_{a}: \quad\left(\left(p_{\text {plan }} \mid C T=\text { more }\right)-\left(p_{\text {plan }} \mid C T=\text { less }\right) \mid \text { importcomp }=\text { yes }\right) \\
\left(\left(p_{\text {plan }} \mid C T=\text { more }\right)-\left(p_{\text {plan }} \mid C T=\text { less }\right) \mid \text { importer }=\text { no }\right)
\end{gathered}
$$

11.

$$
\begin{array}{cc}
\left.H_{0}: \quad\left(p_{\text {plan }} \mid C T=\text { more }\right)-\left(p_{\text {plan }} \mid C T=\text { less }\right) \mid F D I=\text { yes }\right)= \\
\left(\left(p_{\text {plan }} \mid C T=\text { more }\right)-\left(p_{\text {plan }} \mid C T=\text { less }\right) \mid F D I=\text { no }\right) \\
H_{a}: \quad\left(\left(p_{\text {plan }} \mid C T=\text { more }\right)-\left(p_{\text {plan }} \mid C T=\text { less }\right) \mid F D I=\text { yes }\right) \\
\left(\left(p_{\text {plan }} \mid C T=\text { more }\right)-\left(p_{\text {plan }} \mid C T=\text { less }\right) \mid F D I=\text { no }\right)
\end{array}
$$

Furthermore, we expect that the conditional average marginal interaction effects between the cost and compensation/competitiveness attributes of the conjoint will be of greater magnitute for individuals who support the welfare state, who support government intervention, who trust in government, and who lean left politically. To test this, we specify hypotheses that take the form of difference-in-difference-in-differences: 
12.

$$
\begin{aligned}
& H_{0}: \quad\left(\left(p_{\text {plan }} \mid C=\text { lower }\right)-\left(p_{\text {plan }} \mid C=\text { higher }\right) \mid C S=\text { lower }\right)- \\
&\left.\left(\left(p_{\text {plan }} \mid C=\text { lower }\right)-\left(p_{\text {plan }} \mid C=\text { higher }\right) \mid C S=\text { higher }\right) \quad \mid \text { gvtint }=\text { low }\right)= \\
&\left(\left(p_{\text {plan }} \mid C=\text { lower }\right)-\left(p_{\text {plan }} \mid C=\text { higher }\right) \mid C S=\text { lower }\right) \quad- \\
&\left.\left(\left(p_{\text {plan }} \mid C=\text { lower }\right)-\left(p_{\text {plan }} \mid C=\text { higher }\right) \mid C S=\text { higher }\right) \quad \mid \text { gvtint }=\text { high }\right) \\
&\left(\left(p_{\text {plan }} \mid C=\text { lower }\right)-\left(p_{\text {plan }} \mid C=\text { higher }\right) \mid C S=\text { lower }\right) \\
& H_{a}: \quad\left(\left(p_{\text {plan }} \mid C=\text { lower }\right)-\left(p_{\text {plan }} \mid C=\text { higher }\right) \mid C S=\text { higher }\right) \quad- \\
&\left.\left(\left(p_{\text {plan }} \mid C=\text { lower }\right)-\left(p_{\text {plan }} \mid C=\text { higher }\right) \mid C S=\text { lower }\right) \quad \mid \text { gvtint }=\text { low }\right)< \\
&\left(\left(\left(p_{\text {plan }} \mid C=\text { lower }\right)-\left(p_{\text {plan }} \mid C=\text { higher }\right) \mid C S=\text { higher }\right) \quad-\right. \\
&\left.\left(\left(p_{\text {plan }} \mid C=\text { lower }\right)-\left(p_{\text {plan }} \mid C=\text { higher }\right) \mid C S=\text { lower }\right) \quad \mid \text { gvtint }=\text { high }\right) \\
&\left(\left(p_{\text {plan }} \mid C=\text { lower }\right)-\left(p_{\text {plan }} \mid C=\text { higher }\right) \mid C S=\text { higher }\right)
\end{aligned}
$$

13.

$$
\begin{aligned}
H_{0}: \quad\left(\left(p_{\text {plan }} \mid C=\text { lower }\right)-\left(p_{\text {plan }} \mid C=\text { higher }\right) \mid C S=\text { lower }\right) \quad- \\
\left.\left(\left(p_{\text {plan }} \mid C=\text { lower }\right)-\left(p_{\text {plan }} \mid C=\text { higher }\right) \mid C S=\text { higher }\right) \quad \mid \text { gvtred }=\text { low }\right)= \\
\left(\left(\left(p_{\text {plan }} \mid C=\text { lower }\right)-\left(p_{\text {plan }} \mid C=\text { higher }\right) \mid C S=\text { lower }\right) \quad-\right. \\
\left.\left(\left(p_{\text {plan }} \mid C=\text { lower }\right)-\left(p_{\text {plan }} \mid C=\text { higher }\right) \mid C S=\text { higher }\right) \quad \mid \text { gvtred }=\text { high }\right) \\
\left(\left(p_{\text {plan }} \mid C=\text { lower }\right)-\left(p_{\text {plan }} \mid C=\text { higher }\right) \mid C S=\text { lower }\right) \\
H_{a}: \quad\left(\left(p_{\text {plan }} \mid C=\text { lower }\right)-\left(p_{\text {plan }} \mid C=\text { higher }\right) \mid C S=\text { lower }\right) \quad- \\
\left.\left(\left(p_{\text {plan }} \mid C=\text { lower }\right)-\left(p_{\text {plan }} \mid C=\text { higher }\right) \mid C S=\text { lower }\right) \quad \mid \text { gvtred }=\text { low }\right)< \\
\left(\left(\left(p_{\text {plan }} \mid C=\text { lower }\right)-\left(p_{\text {plan }} \mid C=\text { higher }\right) \mid C S=\text { higher }\right) \quad-\right. \\
\left.\left(\left(p_{\text {plan }} \mid C=\text { lower }\right)-\left(p_{\text {plan }} \mid C=\text { higher }\right) \mid C S=\text { lower }\right) \quad \mid \text { gvtred }=\text { high }\right) \\
\left(\left(p_{\text {plan }} \mid C=\text { lower }\right)-\left(p_{\text {plan }} \mid C=\text { higher }\right) \mid C S=\text { higher }\right)
\end{aligned}
$$

14.

$$
\begin{aligned}
& H_{0}: \quad\left(\left(p_{\text {plan }} \mid C=\text { lower }\right)-\left(p_{\text {plan }} \mid C=\text { higher }\right) \mid C S=\text { lower }\right)- \\
&\left.\left(\left(p_{\text {plan }} \mid C=\text { lower }\right)-\left(p_{\text {plan }} \mid C=\text { higher }\right) \mid C S=\text { higher }\right) \quad \mid l-r=\text { right }\right)= \\
&\left(\left(p_{\text {plan }} \mid C=\text { lower }\right)-\left(p_{\text {plan }} \mid C=\text { higher }\right) \mid C S=\text { lower }\right) \quad- \\
&\left.\left(\left(p_{\text {plan }} \mid C=\text { lower }\right)-\left(p_{\text {plan }} \mid C=\text { higher }\right) \mid C S=\text { higher }\right) \quad \mid l-r=\text { left }\right) \\
&\left(\left(p_{\text {plan }} \mid C=\text { lower }\right)-\left(p_{\text {plan }} \mid C=\text { higher }\right) \mid C S=\text { lower }\right) \\
& H_{a}: \quad\left(\left(\left(p_{\text {plan }} \mid C=\text { lower }\right)-\left(p_{\text {plan }} \mid C=\text { higher }\right) \mid C S=\text { higher }\right) \quad-\right. \\
&\left.\quad\left(\left(p_{\text {plan }} \mid C=\text { lower }\right)-\left(p_{\text {plan }} \mid C=\text { higher }\right) \mid C S=\text { lower }\right) \quad \mid l-r=\text { right }\right)< \\
&\left(\left(\left(p_{\text {plan }} \mid C=\text { lower }\right)-\left(p_{\text {plan }} \mid C=\text { higher }\right) \mid C S=\text { higher }\right) \quad-\right. \\
&\left.\quad\left(\left(p_{\text {plan }} \mid C=\text { lower }\right)-\left(p_{\text {plan }} \mid C=\text { higher }\right) \mid C S=\text { lower }\right) \quad \mid l-r=\text { left }\right) \\
&\left(\left(p_{\text {plan }} \mid C=\text { lower }\right)-\left(p_{\text {plan }} \mid C=\text { higher }\right) \mid C S=\text { higher }\right)
\end{aligned}
$$


15.

$$
\begin{aligned}
& H_{0}: \quad\left(\left(p_{\text {plan }} \mid C=\text { lower }\right)-\left(p_{\text {plan }} \mid C=\text { higher }\right) \mid C S=\text { lower }\right)- \\
&\left.\left(\left(p_{\text {plan }} \mid C=\text { lower }\right)-\left(p_{\text {plan }} \mid C=\text { higher }\right) \mid C S=\text { higher }\right) \quad \mid \text { govtrust }=\text { low }\right)= \\
&\left(\left(p_{\text {plan }} \mid C=\text { lower }\right)-\left(p_{\text {plan }} \mid C=\text { higher }\right) \mid C S=\text { lower }\right) \quad- \\
&\left.\left(\left(p_{\text {plan }} \mid C=\text { lower }\right)-\left(p_{\text {plan }} \mid C=\text { higher }\right) \mid C S=\text { higher }\right) \quad \mid \text { govtrust }=\text { high }\right) \\
&\left(\left(p_{\text {plan }} \mid C=\text { lower }\right)-\left(p_{\text {plan }} \mid C=\text { higher }\right) \mid C S=\text { lower }\right) \\
& H_{a}: \quad\left(\left(p_{\text {plan }} \mid C=\text { lower }\right)-\left(p_{\text {plan }} \mid C=\text { higher }\right) \mid C S=\text { higher }\right) \quad- \\
&\left.\left(\left(p_{\text {plan }} \mid C=\text { lower }\right)-\left(p_{\text {plan }} \mid C=\text { higher }\right) \mid C S=\text { lower }\right) \quad \mid \text { govtrust }=\text { low }\right)< \\
&\left(\left(\left(p_{\text {plan }} \mid C=\text { lower }\right)-\left(p_{\text {plan }} \mid C=\text { higher }\right) \mid C S=\text { higher }\right) \quad-\right. \\
&\left.\left(\left(p_{\text {plan }} \mid C=\text { lower }\right)-\left(p_{\text {plan }} \mid C=\text { higher }\right) \mid C S=\text { lower }\right) \quad \mid \text { govtrust }=\text { high }\right) \\
&\left(\left(p_{\text {plan }} \mid C=\text { lower }\right)-\left(p_{\text {plan }} \mid C=\text { higher }\right) \mid C S=\text { higher }\right)
\end{aligned}
$$

16.

$$
\begin{array}{rll}
H_{0}: \quad\left(\left(p_{\text {plan }} \mid C=\text { lower }\right)-\left(p_{\text {plan }} \mid C=\text { higher }\right) \mid C T=\text { less }\right) & - \\
& \left(\left(p_{\text {plan }} \mid C=\text { lower }\right)-\left(p_{\text {plan }} \mid C=\text { higher }\right) \mid C T=\text { more }\right) & \mid \text { gvtint }=\text { low })= \\
\left(\left(\left(p_{\text {plan }} \mid C=\text { lower }\right)-\left(p_{\text {plan }} \mid C=\text { higher }\right) \mid C T=\text { less }\right)\right. & - \\
\left(\left(p_{\text {plan }} \mid C=\text { lower }\right)-\left(p_{\text {plan }} \mid C=\text { higher }\right) \mid C T=\text { more }\right) & \mid \text { gvtint }=\text { high }) \\
& \left(\left(p_{\text {plan }} \mid C=\text { lower }\right)-\left(p_{\text {plan }} \mid C=\text { higher }\right) \mid C T=\text { less }\right) & \\
H_{a}: \quad\left(\left(p_{\text {plan }} \mid C=\text { lower }\right)-\left(p_{\text {plan }} \mid C=\text { higher }\right) \mid C T=\text { more }\right) & - \\
& \left(\left(p_{\text {plan }} \mid C=\text { lower }\right)-\left(p_{\text {plan }} \mid C=\text { higher }\right) \mid C T=\text { less }\right) & \mid \text { gvtint }=\text { low })< \\
\left(\left(p_{\text {plan }} \mid C=\text { lower }\right)-\left(p_{\text {plan }} \mid C=\text { higher }\right) \mid C T=\text { more }\right) & - \\
& \left(\left(p_{\text {plan }} \mid C=\text { lower }\right)-\left(p_{\text {plan }} \mid C=\text { higher }\right) \mid C T=\text { less }\right) & \mid \text { gvtint }=\text { high }) \\
& \left(\left(p_{\text {plan }} \mid C=\text { lower }\right)-\left(p_{\text {plan }} \mid C=\text { higher }\right) \mid C T=\text { more }\right) &
\end{array}
$$

17.

$$
\begin{array}{rll}
H_{0}: & \left(\left(\left(p_{\text {plan }} \mid C=\text { lower }\right)-\left(p_{\text {plan }} \mid C=\text { higher }\right) \mid C T=\text { less }\right)\right. & - \\
& \left(\left(p_{\text {plan }} \mid C=\text { lower }\right)-\left(p_{\text {plan }} \mid C=\text { higher }\right) \mid C T=\text { more }\right) & \mid \text { gvtred }=\text { low })= \\
& \left(\left(\left(p_{\text {plan }} \mid C=\text { lower }\right)-\left(p_{\text {plan }} \mid C=\text { higher }\right) \mid C T=\text { less }\right)\right. & - \\
& \left(\left(p_{\text {plan }} \mid C=\text { lower }\right)-\left(p_{\text {plan }} \mid C=\text { higher }\right) \mid C T=\text { more }\right) & \mid \text { gvtred }=\text { high }) \\
& \left(\left(p_{\text {plan }} \mid C=\text { lower }\right)-\left(p_{\text {plan }} \mid C=\text { higher }\right) \mid C T=\text { less }\right) & \\
H_{a}: \quad\left(\left(\left(p_{\text {plan }} \mid C=\text { lower }\right)-\left(p_{\text {plan }} \mid C=\text { higher }\right) \mid C T=\text { more }\right)\right. & - \\
& \left.\left(\left(p_{\text {plan }} \mid C=\text { lower }\right)-\left(p_{\text {plan }} \mid C=\text { higher }\right) \mid C T=\text { less }\right) \quad \mid \text { gvtred }=\text { low }\right)< \\
& \left(\left(p_{\text {plan }} \mid C=\text { lower }\right)-\left(p_{\text {plan }} \mid C=\text { higher }\right) \mid C T=\text { more }\right) & - \\
& \left(\left(p_{\text {plan }} \mid C=\text { lower }\right)-\left(p_{\text {plan }} \mid C=\text { higher }\right) \mid C T=\text { less }\right) & \mid \text { gvtred }=\text { high }) \\
& \left(\left(p_{\text {plan }} \mid C=\text { lower }\right)-\left(p_{\text {plan }} \mid C=\text { higher }\right) \mid C T=\text { more }\right) &
\end{array}
$$


item

$$
\begin{array}{ccl}
H_{0}: \quad\left(\left(p_{\text {plan }} \mid C=\text { lower }\right)-\left(p_{\text {plan }} \mid C=\text { higher }\right) \mid C T=\text { less }\right) & - \\
\left(\left(p_{\text {plan }} \mid C=\text { lower }\right)-\left(p_{\text {plan }} \mid C=\text { higher }\right) \mid C T=\text { more }\right) & \mid l-r=\text { right })= \\
\left(\left(\left(p_{\text {plan }} \mid C=\text { lower }\right)-\left(p_{\text {plan }} \mid C=\text { higher }\right) \mid C T=\text { less }\right)\right. & - \\
\left(\left(p_{\text {plan }} \mid C=\text { lower }\right)-\left(p_{\text {plan }} \mid C=\text { higher }\right) \mid C T=\text { more }\right) & \mid l-r=\text { left }) \\
& \left(\left(p_{\text {plan }} \mid C=\text { lower }\right)-\left(p_{\text {plan }} \mid C=\text { higher }\right) \mid C T=\text { less }\right) & \\
H_{a}: \quad\left(\left(p_{\text {plan }} \mid C=\text { lower }\right)-\left(p_{\text {plan }} \mid C=\text { higher }\right) \mid C T=\text { more }\right) & - \\
\left(\left(p_{\text {plan }} \mid C=\text { lower }\right)-\left(p_{\text {plan }} \mid C=\text { higher }\right) \mid C T=\text { less }\right) & \mid l-r=\text { right })< \\
\left(\left(p_{\text {plan }} \mid C=\text { lower }\right)-\left(p_{\text {plan }} \mid C=\text { higher }\right) \mid C T=\text { more }\right) & - \\
& \left(\left(p_{\text {plan }} \mid C=\text { lower }\right)-\left(p_{\text {plan }} \mid C=\text { higher }\right) \mid C T=\text { less }\right) & \mid l-r=\text { left }) \\
& \left(\left(p_{\text {plan }} \mid C=\text { lower }\right)-\left(p_{\text {plan }} \mid C=\text { higher }\right) \mid C T=\text { more }\right) &
\end{array}
$$

18.

$$
\begin{array}{ccl}
H_{0}: \quad\left(\left(p_{\text {plan }} \mid C=\text { lower }\right)-\left(p_{\text {plan }} \mid C=\text { higher }\right) \mid C T=\text { less }\right) & - \\
& \left(\left(p_{\text {plan }} \mid C=\text { lower }\right)-\left(p_{\text {plan }} \mid C=\text { higher }\right) \mid C T=\text { more }\right) & \mid \text { govtrust }=\text { low })= \\
\left(\left(\left(p_{\text {plan }} \mid C=\text { lower }\right)-\left(p_{\text {plan }} \mid C=\text { higher }\right) \mid C T=\text { less }\right)\right. & - \\
\left(\left(p_{\text {plan }} \mid C=\text { lower }\right)-\left(p_{\text {plan }} \mid C=\text { higher }\right) \mid C T=\text { more }\right) & \mid \text { govtrust }=\text { high }) \\
& \left(\left(p_{\text {plan }} \mid C=\text { lower }\right)-\left(p_{\text {plan }} \mid C=\text { higher }\right) \mid C T=\text { less }\right) & \\
H_{a}: \quad\left(\left(p_{\text {plan }} \mid C=\text { lower }\right)-\left(p_{\text {plan }} \mid C=\text { higher }\right) \mid C T=\text { more }\right) & - \\
\left(\left(p_{\text {plan }} \mid C=\text { lower }\right)-\left(p_{\text {plan }} \mid C=\text { higher }\right) \mid C T=\text { less }\right) & \mid \text { govtrust }=\text { low })< \\
\left(\left(p_{\text {plan }} \mid C=\text { lower }\right)-\left(p_{\text {plan }} \mid C=\text { higher }\right) \mid C T=\text { more }\right) & - \\
\left(\left(p_{\text {plan }} \mid C=\text { lower }\right)-\left(p_{\text {plan }} \mid C=\text { higher }\right) \mid C T=\text { less }\right) & \mid \text { govtrust }=\text { high }) \\
& \left(\left(p_{\text {plan }} \mid C=\text { lower }\right)-\left(p_{\text {plan }} \mid C=\text { higher }\right) \mid C T=\text { more }\right) &
\end{array}
$$

In addition, we expect that the interaction effect between cost and competitiveness measures in the conjoint table is larger for individuals who are exposed to international competition through their employment (working for an exporting, import-competing, or multinational firm): 
19.

$$
\begin{array}{ccl}
H_{0}: \quad\left(\left(p_{\text {plan }} \mid C=\text { lower }\right)-\left(p_{\text {plan }} \mid C=\text { higher }\right) \mid C T=\text { less }\right) & - \\
\left(\left(p_{\text {plan }} \mid C=\text { lower }\right)-\left(p_{\text {plan }} \mid C=\text { higher }\right) \mid C T=\text { more }\right) & \mid \text { exporter }=\text { no })= \\
& \left(\left(p_{\text {plan }} \mid C=\text { lower }\right)-\left(p_{\text {plan }} \mid C=\text { higher }\right) \mid C T=\text { less }\right) & - \\
\left(\left(p_{\text {plan }} \mid C=\text { lower }\right)-\left(p_{\text {plan }} \mid C=\text { higher }\right) \mid C T=\text { more }\right) & \mid \text { exporter }=\text { yes }) \\
& \left(\left(p_{\text {plan }} \mid C=\text { lower }\right)-\left(p_{\text {plan }} \mid C=\text { higher }\right) \mid C T=\text { less }\right) & \\
H_{a}: \quad\left(\left(\left(p_{\text {plan }} \mid C=\text { lower }\right)-\left(p_{\text {plan }} \mid C=\text { higher }\right) \mid C T=\text { more }\right)\right. & - \\
\left(\left(p_{\text {plan }} \mid C=\text { lower }\right)-\left(p_{\text {plan }} \mid C=\text { higher }\right) \mid C T=\text { less }\right) & \mid \text { exporter }=\text { no })< \\
\left(\left(p_{\text {plan }} \mid C=\text { lower }\right)-\left(p_{\text {plan }} \mid C=\text { higher }\right) \mid C T=\text { more }\right) & - \\
& \left(\left(p_{\text {plan }} \mid C=\text { lower }\right)-\left(p_{\text {plan }} \mid C=\text { higher }\right) \mid C T=\text { less }\right) & \mid \text { exporter }=\text { yes }) \\
& \left(\left(p_{\text {plan }} \mid C=\text { lower }\right)-\left(p_{\text {plan }} \mid C=\text { higher }\right) \mid C T=\text { more }\right) &
\end{array}
$$

20.

$$
\begin{aligned}
& H_{0}: \quad\left(\left(p_{\text {plan }} \mid C=\text { lower }\right)-\left(p_{\text {plan }} \mid C=\text { higher }\right) \mid C T=\text { less }\right) \quad- \\
& \left.\left(\left(p_{\text {plan }} \mid C=\text { lower }\right)-\left(p_{\text {plan }} \mid C=\text { higher }\right) \mid C T=\text { more }\right) \quad \mid \text { importcomp }=\text { no }\right)= \\
& \left(\left(\left(p_{\text {plan }} \mid C=\text { lower }\right)-\left(p_{\text {plan }} \mid C=\text { higher }\right) \mid C T=\text { less }\right) \quad-\right. \\
& \left.\left(\left(p_{\text {plan }} \mid C=\text { lower }\right)-\left(p_{\text {plan }} \mid C=\text { higher }\right) \mid C T=\text { more }\right) \quad \mid \text { importcomp }=\text { yes }\right) \\
& \left(\left(p_{\text {plan }} \mid C=\text { lower }\right)-\left(p_{\text {plan }} \mid C=\text { higher }\right) \mid C T=\text { less }\right) \\
& H_{a}: \quad\left(\left(\left(p_{\text {plan }} \mid C=\text { lower }\right)-\left(p_{\text {plan }} \mid C=\text { higher }\right) \mid C T=\text { more }\right) \quad-\right. \\
& \left.\left(\left(p_{\text {plan }} \mid C=\text { lower }\right)-\left(p_{\text {plan }} \mid C=\text { higher }\right) \mid C T=\text { less }\right) \quad \mid \text { importcomp }=\text { no }\right)< \\
& \left(\left(\left(p_{\text {plan }} \mid C=\text { lower }\right)-\left(p_{\text {plan }} \mid C=\text { higher }\right) \mid C T=\text { more }\right)-\right. \\
& \left.\left(\left(p_{\text {plan }} \mid C=\text { lower }\right)-\left(p_{\text {plan }} \mid C=\text { higher }\right) \mid C T=\text { less }\right) \quad \mid \text { importcomp }=\text { yes }\right) \\
& \left(\left(p_{\text {plan }} \mid C=\text { lower }\right)-\left(p_{\text {plan }} \mid C=\text { higher }\right) \mid C T=\text { more }\right)
\end{aligned}
$$

21.

$$
\begin{array}{rll}
H_{0}: \quad\left(\left(p_{\text {plan }} \mid C=\text { lower }\right)-\left(p_{\text {plan }} \mid C=\text { higher }\right) \mid C T=\text { less }\right) & - \\
& \left(\left(p_{\text {plan }} \mid C=\text { lower }\right)-\left(p_{\text {plan }} \mid C=\text { higher }\right) \mid C T=\text { more }\right) & \mid F D I=\text { no })= \\
& \left(\left(\left(p_{\text {plan }} \mid C=\text { lower }\right)-\left(p_{\text {plan }} \mid C=\text { higher }\right) \mid C T=\text { less }\right)\right. & - \\
& \left(\left(p_{\text {plan }} \mid C=\text { lower }\right)-\left(p_{\text {plan }} \mid C=\text { higher }\right) \mid C T=\text { more }\right) & \mid F D I=\text { yes }) \\
& \left(\left(p_{\text {plan }} \mid C=\text { lower }\right)-\left(p_{\text {plan }} \mid C=\text { higher }\right) \mid C T=\text { less }\right) & \\
H_{a}: \quad\left(\left(\left(p_{\text {plan }} \mid C=\text { lower }\right)-\left(p_{\text {plan }} \mid C=\text { higher }\right) \mid C T=\text { more }\right)\right. & - \\
& \left.\left(\left(p_{\text {plan }} \mid C=\text { lower }\right)-\left(p_{\text {plan }} \mid C=\text { higher }\right) \mid C T=\text { less }\right) \quad \mid F D I=\text { no }\right)< \\
& \left(\left(\left(p_{\text {plan }} \mid C=\text { lower }\right)-\left(p_{\text {plan }} \mid C=\text { higher }\right) \mid C T=\text { more }\right)\right. & - \\
& \left(\left(p_{\text {plan }} \mid C=\text { lower }\right)-\left(p_{\text {plan }} \mid C=\text { higher }\right) \mid C T=\text { less }\right) & \mid F D I=\text { yes }) \\
& \left(\left(p_{\text {plan }} \mid C=\text { lower }\right)-\left(p_{\text {plan }} \mid C=\text { higher }\right) \mid C T=\text { more }\right) &
\end{array}
$$


Similar to our hypotheses above, we expect that the interaction effect of the compensation and competitiveness treatment in the vignette experiment and the cost of the plans in the conjoint is larger among individuals who support the welfare state, who support government intervention, who trust in government, and who lean left politically. For brevity, we use $\mathrm{T}$ to stand in for both T1 and $\mathrm{T} 2$ in the first set of specified hypotheses below. Again, our hypotheses take the form of tripple differences.

22.

$$
\begin{array}{rll}
H_{0}: & \left(\left(p_{\text {plan }} \mid C=\text { lower }\right)-\left(p_{\text {plan }} \mid C=\text { higher }\right) \mid T=C\right) & - \\
& \left.\left(\left(p_{\text {plan }} \mid C=\text { lower }\right)-\left(p_{\text {plan }} \mid C=\text { higher }\right) \mid T=T\right) \quad \mid \text { gvtint }=\text { low }\right)= \\
& \left(\left(p_{\text {plan }} \mid C=\text { lower }\right)-\left(p_{\text {plan }} \mid C=\text { higher }\right) \mid T=C\right)- \\
& \left.\left(\left(p_{\text {plan }} \mid C=\text { lower }\right)-\left(p_{\text {plan }} \mid C=\text { higher }\right) \mid T=T\right) \quad \mid \text { gvtint }=\text { high }\right) \\
& \left(\left(p_{\text {plan }} \mid C=\text { lower }\right)-\left(p_{\text {plan }} \mid C=\text { higher }\right) \mid T=C\right) \\
H_{a}: \quad & \left(\left(p_{\text {plan }} \mid C=\text { lower }\right)-\left(p_{\text {plan }} \mid C=\text { higher }\right) \mid T=T\right) \quad- \\
& \left.\left(\left(p_{\text {plan }} \mid C=\text { lower }\right)-\left(p_{\text {plan }} \mid C=\text { higher }\right) \mid T=C\right) \quad \mid \text { gvtint }=\text { low }\right)< \\
& \left(\left(p_{\text {plan }} \mid C=\text { lower }\right)-\left(p_{\text {plan }} \mid C=\text { higher }\right) \mid T=T\right) \quad- \\
& \left.\left(\left(p_{\text {plan }} \mid C=\text { lower }\right)-\left(p_{\text {plan }} \mid C=\text { higher }\right) \mid T=C\right) \quad \mid \text { gvtint }=\text { high }\right) \\
& \left(\left(p_{\text {plan }} \mid C=\text { lower }\right)-\left(p_{\text {plan }} \mid C=\text { higher }\right) \mid T=T\right)
\end{array}
$$

23.

$$
\begin{aligned}
H_{0}: \quad\left(\left(p_{\text {plan }} \mid C=\text { lower }\right)-\left(p_{\text {plan }} \mid C=\text { higher }\right) \mid T=C\right) & - \\
& \left.\left(\left(p_{\text {plan }} \mid C=\text { lower }\right)-\left(p_{\text {plan }} \mid C=\text { higher }\right) \mid T=T\right) \quad \mid l-r=\text { right }\right)= \\
& \left(\left(\left(p_{\text {plan }} \mid C=\text { lower }\right)-\left(p_{\text {plan }} \mid C=\text { higher }\right) \mid T=C\right)-\right. \\
& \left.\left(\left(p_{\text {plan }} \mid C=\text { lower }\right)-\left(p_{\text {plan }} \mid C=\text { higher }\right) \mid T=T\right) \quad \mid l-r=\text { left }\right) \\
& \left(\left(p_{\text {plan }} \mid C=\text { lower }\right)-\left(p_{\text {plan }} \mid C=\text { higher }\right) \mid T=C\right) \\
H_{a}: \quad & \left(\left(p_{\text {plan }} \mid C=\text { lower }\right)-\left(p_{\text {plan }} \mid C=\text { higher }\right) \mid T=T\right) \quad- \\
& \left.\left(\left(p_{\text {plan }} \mid C=\text { lower }\right)-\left(p_{\text {plan }} \mid C=\text { higher }\right) \mid T=C\right) \quad \mid l-r=\text { right }\right)< \\
& \left(\left(p_{\text {plan }} \mid C=\text { lower }\right)-\left(p_{\text {plan }} \mid C=\text { higher }\right) \mid T=T\right)- \\
& \left.\left(\left(p_{\text {plan }} \mid C=\text { lower }\right)-\left(p_{\text {plan }} \mid C=\text { higher }\right) \mid T=C\right) \quad \mid l-r=\text { left }\right) \\
& \left(\left(p_{\text {plan }} \mid C=\text { lower }\right)-\left(p_{\text {plan }} \mid C=\text { higher }\right) \mid T=T\right)
\end{aligned}
$$


24 .

$$
\begin{aligned}
H_{0}: & \left(\left(p_{\text {plan }} \mid C=\text { lower }\right)-\left(p_{\text {plan }} \mid C=\text { higher }\right) \mid C S=\text { lower }\right)- \\
& \left.\left(\left(p_{\text {plan }} \mid C=\text { lower }\right)-\left(p_{\text {plan }} \mid C=\text { higher }\right) \mid C S=\text { higher }\right) \quad \mid l-r=\text { right }\right)= \\
& \left(\left(p_{\text {plan }} \mid C=\text { lower }\right)-\left(p_{\text {plan }} \mid C=\text { higher }\right) \mid C S=\text { lower }\right)- \\
& \left.\left(\left(p_{\text {plan }} \mid C=\text { lower }\right)-\left(p_{\text {plan }} \mid C=\text { higher }\right) \mid C S=\text { higher }\right) \quad \mid l-r=\text { left }\right) \\
& \left(\left(p_{\text {plan }} \mid C=\text { lower }\right)-\left(p_{\text {plan }} \mid C=\text { higher }\right) \mid C S=\text { higher }\right) \\
H_{a}: & \left(\left(\left(p_{\text {plan }} \mid C=\text { lower }\right)-\left(p_{\text {plan }} \mid C=\text { higher }\right) \mid C S=\text { lower }\right)-\right. \\
& \left.\left(\left(p_{\text {plan }} \mid C=\text { lower }\right)-\left(p_{\text {plan }} \mid C=\text { higher }\right) \mid C S=\text { higher }\right) \quad \mid l-r=\text { right }\right)< \\
& \left(\left(\left(p_{\text {plan }} \mid C=\text { lower }\right)-\left(p_{\text {plan }} \mid C=\text { higher }\right) \mid C S=\text { lower }\right)-\right. \\
& \left.\left(\left(p_{\text {plan }} \mid C=\text { lower }\right)-\left(p_{\text {plan }} \mid C=\text { higher }\right) \mid C S=\text { higher }\right) \quad \mid l-r=\text { left }\right) \\
& \left(\left(p_{\text {plan }} \mid C=\text { lower }\right)-\left(p_{\text {plan }} \mid C=\text { higher }\right) \mid C S=\text { higher }\right)
\end{aligned}
$$

25.

$$
\begin{array}{rll}
H_{0}: & \left(\left(p_{\text {plan }} \mid C=\text { lower }\right)-\left(p_{\text {plan }} \mid C=\text { higher }\right) \mid T=C\right) & - \\
& \left.\left(\left(p_{\text {plan }} \mid C=\text { lower }\right)-\left(p_{\text {plan }} \mid C=\text { higher }\right) \mid T=T\right) \quad \mid \text { govtrust }=\text { low }\right)= \\
& \left(\left(p_{\text {plan }} \mid C=\text { lower }\right)-\left(p_{\text {plan }} \mid C=\text { higher }\right) \mid T=C\right) & - \\
& \left.\left(\left(p_{\text {plan }} \mid C=\text { lower }\right)-\left(p_{\text {plan }} \mid C=\text { higher }\right) \mid T=T\right) \quad \mid \text { govtrust }=\text { high }\right) \\
& \left(\left(p_{\text {plan }} \mid C=\text { lower }\right)-\left(p_{\text {plan }} \mid C=\text { higher }\right) \mid T=C\right) \\
H_{a}: \quad & \left(\left(p_{\text {plan }} \mid C=\text { lower }\right)-\left(p_{\text {plan }} \mid C=\text { higher }\right) \mid T=T\right) & - \\
& \left.\left(\left(p_{\text {plan }} \mid C=\text { lower }\right)-\left(p_{\text {plan }} \mid C=\text { higher }\right) \mid T=C\right) \quad \mid \text { govtrust }=\text { low }\right)< \\
& \left(\left(\left(p_{\text {plan }} \mid C=\text { lower }\right)-\left(p_{\text {plan }} \mid C=\text { higher }\right) \mid T=T\right)-\right. \\
& \left.\left(\left(p_{\text {plan }} \mid C=\text { lower }\right)-\left(p_{\text {plan }} \mid C=\text { higher }\right) \mid T=C\right) \quad \mid \text { govtrust }=\text { high }\right) \\
& \left(\left(p_{\text {plan }} \mid C=\text { lower }\right)-\left(p_{\text {plan }} \mid C=\text { higher }\right) \mid T=T\right)
\end{array}
$$

For the same subgroups of individuals as above, we further expect that the interaction effect between the compensation treatment in the vignette experiment and the compensation variables in the conjoint table is larger. In addition, we expect that the interaction effect between the competitiveness treatment in the vignette experiment and the competitiveness variables in the conjoint table is larger for the above mentioned groups of individuals. 
26.

$$
\begin{array}{rll}
H_{0}: & \left(\left(p_{\text {plan }} \mid C S=\text { higher }\right)-\left(p_{\text {plan }} \mid C S=\text { lower }\right) \mid T=T 1\right) & - \\
& \left(\left(p_{\text {plan }} \mid C S=\text { higher }\right)-\left(p_{\text {plan }} \mid C S=\text { lower }\right) \mid T=C\right) & \mid \text { gvtint }=\text { low })= \\
& \left(\left(p_{\text {plan }} \mid C S=\text { higher }\right)-\left(p_{\text {plan }} \mid C S=\text { lower }\right) \mid T=T 1\right) & - \\
& \left(\left(p_{\text {plan }} \mid C S=\text { higher }\right)-\left(p_{\text {plan }} \mid C S=\text { lower }\right) \mid T=C\right) & \mid \text { gvtint }=\text { high }) \\
& \left(\left(p_{\text {plan }} \mid C S=\text { higher }\right)-\left(p_{\text {plan }} \mid C S=\text { lower }\right) \mid T=T 1\right) & \\
H_{a}: \quad\left(\left(\left(p_{\text {plan }} \mid C S=\text { higher }\right)-\left(p_{\text {plan }} \mid C S=\text { lower }\right) \mid T=C\right)\right. & - \\
\left(\left(p_{\text {plan }} \mid C S=\text { higher }\right)-\left(p_{\text {plan }} \mid C S=\text { lower }\right) \mid T=T 1\right) & \mid \text { gvtint }=\text { low })< \\
& \left(\left(p_{\text {plan }} \mid C S=\text { higher }\right)-\left(p_{\text {plan }} \mid C S=\text { lower }\right) \mid T=C\right) & - \\
& \left(\left(p_{\text {plan }} \mid C S=\text { higher }\right)-\left(p_{\text {plan }} \mid C S=\text { lower }\right) \mid T=T 1\right) & \mid \text { gvtint }=\text { high }) \\
& \left(\left(p_{\text {plan }} \mid C S=\text { higher }\right)-\left(p_{\text {plan }} \mid C S=\text { lower }\right) \mid T=C\right) &
\end{array}
$$

27.

$$
\begin{array}{rll}
H_{0}: & \left(\left(p_{\text {plan }} \mid C S=\text { higher }\right)-\left(p_{\text {plan }} \mid C S=\text { lower }\right) \mid T=T 1\right) & - \\
& \left(\left(p_{\text {plan }} \mid C S=\text { higher }\right)-\left(p_{\text {plan }} \mid C S=\text { lower }\right) \mid T=C\right) & \mid \text { gvtred }=\text { low })= \\
& \left(\left(p_{\text {plan }} \mid C S=\text { higher }\right)-\left(p_{\text {plan }} \mid C S=\text { lower }\right) \mid T=T 1\right) & - \\
& \left(\left(p_{\text {plan }} \mid C S=\text { higher }\right)-\left(p_{\text {plan }} \mid C S=\text { lower }\right) \mid T=C\right) & \mid \text { gvtred }=\text { high }) \\
& \left(\left(p_{\text {plan }} \mid C S=\text { higher }\right)-\left(p_{\text {plan }} \mid C S=\text { lower }\right) \mid T=T 1\right) & \\
H_{a}: \quad\left(\left(p_{\text {plan }} \mid C S=\text { higher }\right)-\left(p_{\text {plan }} \mid C S=\text { lower }\right) \mid T=C\right) & - \\
& \left.\left(\left(p_{\text {plan }} \mid C S=\text { higher }\right)-\left(p_{\text {plan }} \mid C S=\text { lower }\right) \mid T=T 1\right) \quad \mid \text { gvtred }=\text { low }\right)< \\
& \left(\left(\left(p_{\text {plan }} \mid C S=\text { higher }\right)-\left(p_{\text {plan }} \mid C S=\text { lower }\right) \mid T=C\right)\right. & - \\
& \left(\left(p_{\text {plan }} \mid C S=\text { higher }\right)-\left(p_{\text {plan }} \mid C S=\text { lower }\right) \mid T=T 1\right) & \mid \text { gvtred }=\text { high }) \\
& \left(\left(p_{\text {plan }} \mid C S=\text { higher }\right)-\left(p_{\text {plan }} \mid C S=\text { lower }\right) \mid T=C\right) &
\end{array}
$$

28.

$$
\begin{array}{rll}
H_{0}: & \left(\left(p_{\text {plan }} \mid C S=\text { higher }\right)-\left(p_{\text {plan }} \mid C S=\text { lower }\right) \mid T=T 1\right) & - \\
& \left(\left(p_{\text {plan }} \mid C S=\text { higher }\right)-\left(p_{\text {plan }} \mid C S=\text { lower }\right) \mid T=C\right) & \mid l-r=\text { right })= \\
& \left(\left(p_{\text {plan }} \mid C S=\text { higher }\right)-\left(p_{\text {plan }} \mid C S=\text { lower }\right) \mid T=T 1\right) & - \\
& \left(\left(p_{\text {plan }} \mid C S=\text { higher }\right)-\left(p_{\text {plan }} \mid C S=\text { lower }\right) \mid T=C\right) & \mid l-r=\text { left }) \\
& \left(\left(p_{\text {plan }} \mid C S=\text { higher }\right)-\left(p_{\text {plan }} \mid C S=\text { lower }\right) \mid T=T 1\right) & \\
H_{a}: \quad\left(\left(\left(p_{\text {plan }} \mid C S=\text { higher }\right)-\left(p_{\text {plan }} \mid C S=\text { lower }\right) \mid T=C\right)\right. & - \\
& \left.\left(\left(p_{\text {plan }} \mid C S=\text { higher }\right)-\left(p_{\text {plan }} \mid C S=\text { lower }\right) \mid T=T 1\right) \quad \mid l-r=\text { right }\right)< \\
& \left(\left(\left(p_{\text {plan }} \mid C S=\text { higher }\right)-\left(p_{\text {plan }} \mid C S=\text { lower }\right) \mid T=C\right)\right. & - \\
& \left(\left(p_{\text {plan }} \mid C S=\text { higher }\right)-\left(p_{\text {plan }} \mid C S=\text { lower }\right) \mid T=T 1\right) & \mid l-r=\text { left }) \\
& \left(\left(p_{\text {plan }} \mid C S=\text { higher }\right)-\left(p_{\text {plan }} \mid C S=\text { lower }\right) \mid T=C\right) &
\end{array}
$$


29.

$$
\begin{array}{ccl}
H_{0}: & \left(\left(p_{\text {plan }} \mid C S=\text { higher }\right)-\left(p_{\text {plan }} \mid C S=\text { lower }\right) \mid T=T 1\right) & - \\
& \left(\left(p_{\text {plan }} \mid C S=\text { higher }\right)-\left(p_{\text {plan }} \mid C S=\text { lower }\right) \mid T=C\right) & \mid \text { govtrust }=\text { low })= \\
& \left(\left(p_{\text {plan }} \mid C S=\text { higher }\right)-\left(p_{\text {plan }} \mid C S=\text { lower }\right) \mid T=T 1\right) & - \\
& \left(\left(p_{\text {plan }} \mid C S=\text { higher }\right)-\left(p_{\text {plan }} \mid C S=\text { lower }\right) \mid T=C\right) & \mid \text { govtrust }=\text { high }) \\
& \left(\left(p_{\text {plan }} \mid C S=\text { higher }\right)-\left(p_{\text {plan }} \mid C S=\text { lower }\right) \mid T=T 1\right) & \\
H_{a}: \quad & \left(\left(p_{\text {plan }} \mid C S=\text { higher }\right)-\left(p_{\text {plan }} \mid C S=\text { lower }\right) \mid T=C\right) & - \\
& \left(\left(p_{\text {plan }} \mid C S=\text { higher }\right)-\left(p_{\text {plan }} \mid C S=\text { lower }\right) \mid T=T 1\right) & \mid \text { govtrust }=\text { low })< \\
& \left(\left(p_{\text {plan }} \mid C S=\text { higher }\right)-\left(p_{\text {plan }} \mid C S=\text { lower }\right) \mid T=C\right) & - \\
& \left(\left(p_{\text {plan }} \mid C S=\text { higher }\right)-\left(p_{\text {plan }} \mid C S=\text { lower }\right) \mid T=T 1\right) & \mid \text { govtrust }=\text { high }) \\
& \left(\left(p_{\text {plan }} \mid C S=\text { higher }\right)-\left(p_{\text {plan }} \mid C S=\text { lower }\right) \mid T=C\right) &
\end{array}
$$

30.

$$
\begin{array}{rll}
H_{0}: & \left(\left(p_{\text {plan }} \mid C T=\text { more }\right)-\left(p_{\text {plan }} \mid C T=\text { less }\right) \mid T=T 2\right) & - \\
& \left(\left(p_{\text {plan }} \mid C T=\text { more }\right)-\left(p_{\text {plan }} \mid C T=\text { less }\right) \mid T=C\right) & \mid \text { gvtint }=\text { low })= \\
& \left(\left(\left(p_{\text {plan }} \mid C T=\text { more }\right)-\left(p_{\text {plan }} \mid C T=\text { less }\right) \mid T=T 2\right)\right. & - \\
& \left(\left(p_{\text {plan }} \mid C T=\text { more }\right)-\left(p_{\text {plan }} \mid C T=\text { less }\right) \mid T=C\right) & \mid \text { gvtint }=\text { high }) \\
& \left(\left(p_{\text {plan }} \mid C T=\text { more }\right)-\left(p_{\text {plan }} \mid C T=\text { less }\right) \mid T=T 2\right) & \\
H_{a}: \quad & \left(\left(p_{\text {plan }} \mid C T=\text { more }\right)-\left(p_{\text {plan }} \mid C T=\text { less }\right) \mid T=C\right) & - \\
& \left(\left(p_{\text {plan }} \mid C T=\text { more }\right)-\left(p_{\text {plan }} \mid C T=\text { less }\right) \mid T=T 2\right) & \mid \text { gvtint }=\text { low })< \\
& \left(\left(\left(p_{\text {plan }} \mid C T=\text { more }\right)-\left(p_{\text {plan }} \mid C T=\text { less }\right) \mid T=C\right)\right. & - \\
& \left(\left(p_{\text {plan }} \mid C T=\text { more }\right)-\left(p_{\text {plan }} \mid C T=\text { less }\right) \mid T=T 2\right) & \mid \text { gvtint }=\text { high }) \\
& \left(\left(p_{\text {plan }} \mid C T=\text { more }\right)-\left(p_{\text {plan }} \mid C T=\text { less }\right) \mid T=C\right) &
\end{array}
$$

31.

$$
\begin{array}{rll}
H_{0}: & \left(\left(\left(p_{\text {plan }} \mid C T=\text { more }\right)-\left(p_{\text {plan }} \mid C T=\text { less }\right) \mid T=T 2\right)\right. & - \\
& \left(\left(p_{\text {plan }} \mid C T=\text { more }\right)-\left(p_{\text {plan }} \mid C T=\text { less }\right) \mid T=C\right) & \mid \text { gvtred }=\text { low })= \\
& \left(\left(\left(p_{\text {plan }} \mid C T=\text { more }\right)-\left(p_{\text {plan }} \mid C T=\text { less }\right) \mid T=T 2\right)\right. & - \\
& \left(\left(p_{\text {plan }} \mid C T=\text { more }\right)-\left(p_{\text {plan }} \mid C T=\text { less }\right) \mid T=C\right) & \mid \text { gvtred }=\text { high }) \\
& \left(\left(p_{\text {plan }} \mid C T=\text { more }\right)-\left(p_{\text {plan }} \mid C T=\text { less }\right) \mid T=T 2\right) & \\
H_{a}: \quad & \left(\left(p_{\text {plan }} \mid C T=\text { more }\right)-\left(p_{\text {plan }} \mid C T=\text { less }\right) \mid T=C\right) & - \\
& \left(\left(p_{\text {plan }} \mid C T=\text { more }\right)-\left(p_{\text {plan }} \mid C T=\text { less }\right) \mid T=T 2\right) & \mid \text { gvtred }=\text { low })< \\
& \left(\left(\left(p_{\text {plan }} \mid C T=\text { more }\right)-\left(p_{\text {plan }} \mid C T=\text { less }\right) \mid T=C\right)\right. & - \\
& \left(\left(p_{\text {plan }} \mid C T=\text { more }\right)-\left(p_{\text {plan }} \mid C T=\text { less }\right) \mid T=T 2\right) & \mid \text { gvtred }=\text { high }) \\
& \left(\left(p_{\text {plan }} \mid C T=\text { more }\right)-\left(p_{\text {plan }} \mid C T=\text { less }\right) \mid T=C\right) &
\end{array}
$$


32.

$$
\begin{array}{rll}
H_{0}: & \left(\left(p_{\text {plan }} \mid C T=\text { more }\right)-\left(p_{\text {plan }} \mid C T=\text { less }\right) \mid T=T 2\right) & - \\
& \left(\left(p_{\text {plan }} \mid C T=\text { more }\right)-\left(p_{\text {plan }} \mid C T=\text { less }\right) \mid T=C\right) & \mid l-r=\text { right })= \\
& \left(\left(\left(p_{\text {plan }} \mid C T=\text { more }\right)-\left(p_{\text {plan }} \mid C T=\text { less }\right) \mid T=T 2\right)\right. & - \\
& \left(\left(p_{\text {plan }} \mid C T=\text { more }\right)-\left(p_{\text {plan }} \mid C T=\text { less }\right) \mid T=C\right) & \mid l-r=\text { left }) \\
& \left(\left(p_{\text {plan }} \mid C T=\text { more }\right)-\left(p_{\text {plan }} \mid C T=\text { less }\right) \mid T=T 2\right) & \\
H_{a}: \quad & \left(\left(p_{\text {plan }} \mid C T=\text { more }\right)-\left(p_{\text {plan }} \mid C T=\text { less }\right) \mid T=C\right) & - \\
& \left(\left(p_{\text {plan }} \mid C T=\text { more }\right)-\left(p_{\text {plan }} \mid C T=\text { less }\right) \mid T=T 2\right) & \mid l-r=\text { right })< \\
& \left(\left(\left(p_{\text {plan }} \mid C T=\text { more }\right)-\left(p_{\text {plan }} \mid C T=\text { less }\right) \mid T=C\right)\right. & - \\
& \left(\left(p_{\text {plan }} \mid C T=\text { more }\right)-\left(p_{\text {plan }} \mid C T=\text { less }\right) \mid T=T 2\right) & \mid l-r=\text { left }) \\
& \left(\left(p_{\text {plan }} \mid C T=\text { more }\right)-\left(p_{\text {plan }} \mid C T=\text { less }\right) \mid T=C\right) &
\end{array}
$$

33.

$$
\begin{array}{rll}
H_{0}: & \left(\left(p_{\text {plan }} \mid C T=\text { more }\right)-\left(p_{\text {plan }} \mid C T=\text { less }\right) \mid T=T 2\right) & - \\
& \left(\left(p_{\text {plan }} \mid C T=\text { more }\right)-\left(p_{\text {plan }} \mid C T=\text { less }\right) \mid T=C\right) & \mid \text { govtrust }=\text { low })= \\
& \left(\left(\left(p_{\text {plan }} \mid C T=\text { more }\right)-\left(p_{\text {plan }} \mid C T=\text { less }\right) \mid T=T 2\right)\right. & - \\
& \left(\left(p_{\text {plan }} \mid C T=\text { more }\right)-\left(p_{\text {plan }} \mid C T=\text { less }\right) \mid T=C\right) & \mid \text { govtrust }=\text { high }) \\
& \left(\left(p_{\text {plan }} \mid C T=\text { more }\right)-\left(p_{\text {plan }} \mid C T=\text { less }\right) \mid T=T 2\right) & \\
H_{a}: \quad & \left(\left(\left(p_{\text {plan }} \mid C T=\text { more }\right)-\left(p_{\text {plan }} \mid C T=\text { less }\right) \mid T=C\right)\right. & - \\
& \left(\left(p_{\text {plan }} \mid C T=\text { more }\right)-\left(p_{\text {plan }} \mid C T=\text { less }\right) \mid T=T 2\right) & \mid \text { govtrust }=\text { low })< \\
& \left(\left(\left(p_{\text {plan }} \mid C T=\text { more }\right)-\left(p_{\text {plan }} \mid C T=\text { less }\right) \mid T=C\right)\right. & - \\
& \left(\left(p_{\text {plan }} \mid C T=\text { more }\right)-\left(p_{\text {plan }} \mid C T=\text { less }\right) \mid T=T 2\right) & \mid \text { govtrust }=\text { high }) \\
& \left(\left(p_{\text {plan }} \mid C T=\text { more }\right)-\left(p_{\text {plan }} \mid C T=\text { less }\right) \mid T=C\right)
\end{array}
$$

Lastly, we expect that individuals who are exposed to the international market through their employment working for an exporting, import competing or multinational firm that engages in FDI) should respond more strongly to the competitiveness treatment: 
1.

$$
\begin{array}{rll}
H_{0}: & \left(\left(p_{\text {plan }} \mid C T=\text { more }\right)-\left(p_{\text {plan }} \mid C T=\text { less }\right) \mid T=T 2\right) & - \\
& \left(\left(p_{\text {plan }} \mid C T=\text { more }\right)-\left(p_{\text {plan }} \mid C T=\text { less }\right) \mid T=C\right) & \mid \text { exporter }=\text { no })= \\
& \left(\left(\left(p_{\text {plan }} \mid C T=\text { more }\right)-\left(p_{\text {plan }} \mid C T=\text { less }\right) \mid T=T 2\right)\right. & - \\
& \left(\left(p_{\text {plan }} \mid C T=\text { more }\right)-\left(p_{\text {plan }} \mid C T=\text { less }\right) \mid T=C\right) & \mid \text { exporter }=\text { yes }) \\
& \left(\left(p_{\text {plan }} \mid C T=\text { more }\right)-\left(p_{\text {plan }} \mid C T=\text { less }\right) \mid T=T 2\right) & \\
H_{a}: \quad & \left(\left(p_{\text {plan }} \mid C T=\text { more }\right)-\left(p_{\text {plan }} \mid C T=\text { less }\right) \mid T=C\right) & - \\
& \left(\left(p_{\text {plan }} \mid C T=\text { more }\right)-\left(p_{\text {plan }} \mid C T=\text { less }\right) \mid T=T 2\right) & \mid \text { exporter }=\text { no })< \\
& \left(\left(\left(p_{\text {plan }} \mid C T=\text { more }\right)-\left(p_{\text {plan }} \mid C T=\text { less }\right) \mid T=C\right)\right. & - \\
& \left(\left(p_{\text {plan }} \mid C T=\text { more }\right)-\left(p_{\text {plan }} \mid C T=\text { less }\right) \mid T=T 2\right) & \mid \text { exporter }=y e s) \\
& \left(\left(p_{\text {plan }} \mid C T=\text { more }\right)-\left(p_{\text {plan }} \mid C T=\text { less }\right) \mid T=C\right) &
\end{array}
$$

2.

$$
\begin{array}{rll}
H_{0}: & \left(\left(p_{\text {plan }} \mid C T=\text { more }\right)-\left(p_{\text {plan }} \mid C T=\text { less }\right) \mid T=T 2\right) & - \\
& \left(\left(p_{\text {plan }} \mid C T=\text { more }\right)-\left(p_{\text {plan }} \mid C T=\text { less }\right) \mid T=C\right) & \mid \text { importcomp }=\text { no })= \\
& \left(\left(\left(p_{\text {plan }} \mid C T=\text { more }\right)-\left(p_{\text {plan }} \mid C T=\text { less }\right) \mid T=T 2\right)\right. & - \\
& \left(\left(p_{\text {plan }} \mid C T=\text { more }\right)-\left(p_{\text {plan }} \mid C T=\text { less }\right) \mid T=C\right) & \mid \text { importcomp }=\text { yes }) \\
& \left(\left(p_{\text {plan }} \mid C T=\text { more }\right)-\left(p_{\text {plan }} \mid C T=\text { less }\right) \mid T=T 2\right) & \\
H_{a}: \quad & \left(\left(p_{\text {plan }} \mid C T=\text { more }\right)-\left(p_{\text {plan }} \mid C T=\text { less }\right) \mid T=C\right) & - \\
& \left(\left(p_{\text {plan }} \mid C T=\text { more }\right)-\left(p_{\text {plan }} \mid C T=\text { less }\right) \mid T=T 2\right) & \mid \text { importcomp }=\text { no })< \\
& \left(\left(p_{\text {plan }} \mid C T=\text { more }\right)-\left(p_{\text {plan }} \mid C T=\text { less }\right) \mid T=C\right) & - \\
& \left(\left(p_{\text {plan }} \mid C T=\text { more }\right)-\left(p_{\text {plan }} \mid C T=\text { less }\right) \mid T=T 2\right) & \mid \text { importcomp }=\text { yes }) \\
& \left(\left(p_{\text {plan }} \mid C T=\text { more }\right)-\left(p_{\text {plan }} \mid C T=\text { less }\right) \mid T=C\right) &
\end{array}
$$

3.

$$
\begin{array}{rll}
H_{0}: & \left(\left(p_{\text {plan }} \mid C T=\text { more }\right)-\left(p_{\text {plan }} \mid C T=\text { less }\right) \mid T=T 2\right) & - \\
& \left(\left(p_{\text {plan }} \mid C T=\text { more }\right)-\left(p_{\text {plan }} \mid C T=\text { less }\right) \mid T=C\right) & \mid F D I=\text { no })= \\
& \left(\left(\left(p_{\text {plan }} \mid C T=\text { more }\right)-\left(p_{\text {plan }} \mid C T=\text { less }\right) \mid T=T 2\right)\right. & - \\
& \left(\left(p_{\text {plan }} \mid C T=\text { more }\right)-\left(p_{\text {plan }} \mid C T=\text { less }\right) \mid T=C\right) & \mid F D I=\text { yes }) \\
& \left(\left(p_{\text {plan }} \mid C T=\text { more }\right)-\left(p_{\text {plan }} \mid C T=\text { less }\right) \mid T=T 2\right) & \\
H_{a}: \quad & \left(\left(p_{\text {plan }} \mid C T=\text { more }\right)-\left(p_{\text {plan }} \mid C T=\text { less }\right) \mid T=C\right) & - \\
& \left.\left(\left(p_{\text {plan }} \mid C T=\text { more }\right)-\left(p_{\text {plan }} \mid C T=\text { less }\right) \mid T=T 2\right) \quad \mid F D I=\text { no }\right)< \\
& \left(\left(\left(p_{\text {plan }} \mid C T=\text { more }\right)-\left(p_{\text {plan }} \mid C T=\text { less }\right) \mid T=C\right)\right. & - \\
& \left(\left(p_{\text {plan }} \mid C T=\text { more }\right)-\left(p_{\text {plan }} \mid C T=\text { less }\right) \mid T=T 2\right) & \mid F D I=\text { yes }) \\
& \left(\left(p_{\text {plan }} \mid C T=\text { more }\right)-\left(p_{\text {plan }} \mid C T=\text { less }\right) \mid T=C\right)
\end{array}
$$




\section{References}

Hainmueller, J., Hopkins, D. J., \& Yamamoto, T. (2014). Causal Inference in Conjoint Analysis: Understanding Multidimensional Choices via Stated Preference Experiments. Political Analysis, 22(1), 1-30.

Kane, J. V., Velez, Y. R., \& Barabas, J. (2020). Analyze the Attentive \& Bypass Bias: Mock Vignette Checks in Survey Experiments. 